\title{
Optimization of Integrated Reservoir, Wellbore, and Power Plant Models for Enhanced Geothermal Systems
}

\author{
Jason Peluchette \\ West Virginia University
}

Follow this and additional works at: https://researchrepository.wvu.edu/etd

\section{Recommended Citation}

Peluchette, Jason, "Optimization of Integrated Reservoir, Wellbore, and Power Plant Models for Enhanced Geothermal Systems" (2013). Graduate Theses, Dissertations, and Problem Reports. 3412.

https://researchrepository.wvu.edu/etd/3412

This Thesis is protected by copyright and/or related rights. It has been brought to you by the The Research Repository @ WVU with permission from the rights-holder(s). You are free to use this Thesis in any way that is permitted by the copyright and related rights legislation that applies to your use. For other uses you must obtain permission from the rights-holder(s) directly, unless additional rights are indicated by a Creative Commons license in the record and/ or on the work itself. This Thesis has been accepted for inclusion in WVU Graduate Theses, Dissertations, and Problem Reports collection by an authorized administrator of The Research Repository @ WVU. For more information, please contact researchrepository@mail.wvu.edu. 


\title{
Optimization of Integrated Reservoir, Wellbore, and Power Plant Models for Enhanced Geothermal Systems
}

\author{
Jason Peluchette \\ Thesis submitted to the \\ Benjamin M. Statler College of Engineering and Mineral Resources \\ at West Virginia University \\ in partial fulfillment of the requirements \\ for the degree of
}

Master of Science

in

Chemical Engineering

Dr. Brian Anderson

Dr. Fernando Lima

Dr. Hema Siriwardane

Department of Chemical Engineering

Morgantown, WV

2013

Keywords: Geothermal optimization, Enhanced Geothermal Systems, EGS, wellbore model, reservoir modeling, fractures, geothermal surface plant, flash-steam power plant, Newberry Geothermal 


\begin{abstract}
Optimization of Integrated Reservoir, Wellbore, and Power Plant Models for Enhanced

Geothermal Systems
\end{abstract}

Jason Peluchette

Geothermal energy has the potential to become a substantially greater contributor to the U.S. energy market. An adequate investment in Enhanced Geothermal Systems (EGS) technology will be necessary in order to realize the potential of geothermal energy. This study presents an optimization of a waterbased Enhanced Geothermal System (EGS) modeled for AltaRock Energy's Newberry EGS Demonstration location. The optimization successfully integrates all three components of the geothermal system: (1) the present wellbore design, (2) the reservoir design, and (3) the surface plant design.

Since the Newberry EGS Demonstration will use an existing well (NWG 55-29), there is no optimization of the wellbore design, and the aim of the study for this component is to replicate the present wellbore conditions and design. An in-house wellbore model is used to accurately reflect the temperature and pressure changes that occur in the wellbore fluid and the surrounding casing, cement, and earth during injection and production. For the reservoir design, the existing conditions, such as temperature and pressure at depth and rock density, are incorporated into the model, and several design variables are investigated. The engineered reservoir is modeled using the reservoir simulator TOUGH2 while using the graphical interface PetraSim for visualization. Several fracture networks are investigated with the goal of determining which fracture network yields the greatest electrical output when optimized jointly with the surface plant. A topological optimization of the surface is completed to determine what type of power plant is best suited for this location, and a parametric optimization of the surface plant is completed to determine the optimal operating conditions.

The conditions present at the Newberry, Oregon EGS project site are the basis for this optimization. The subsurface conditions are favorable for the production of electricity from geothermal energy with rock temperatures exceeding $300^{\circ} \mathrm{C}$ at a well depth of $3 \mathrm{~km}$. This research was completed in collaboration with AltaRock Energy, which has provided our research group with data from the Newberry well. The purpose of this thesis is to determine the optimal conditions for operating an Enhanced Geothermal System for the production of electricity at Newberry.

It was determined that a fracture network consisting of five fractured zones carrying $15 \mathrm{~kg} / \mathrm{s}$ of fluid is the best reservoir design out of those investigated in this study. Also, it was found that $100 \mathrm{~m}$ spacing between the fractured zones should be implemented as opposed to only $50 \mathrm{~m}$ of spacing. A double-flash steam power plant provides the best method of utilization of the geothermal fluid. For the maximum amount of electricity generation over the 30-year operating lifetime, the cyclone separator should operate at $205^{\circ} \mathrm{C}$ and the flash vessel should operate at $125^{\circ} \mathrm{C}$. 


\section{ACKNOWLEDGMENTS}

First and foremost I would like to thank my research advisor Dr. Brian Anderson for the opportunity to work on this research and for the funding that he has provided. I would also like to thank him for all the help that he has given me that aided in my completion of this research. I am thankful for the opportunity to be a part of his research group and learn from him, whether it be in group meetings, individual meetings, conference calls, or just in general conversations. I am thankful for our trips to Cornell, Stanford, and other locations that would not have been possible if not for Dr. Anderson. They not only served as great learning experiences, but I also had a very enjoyable time getting to see new places and meet new people. I can honestly say that I have thoroughly enjoyed my graduate school experience, and he is largely responsible for this.

I would like to thank my committee members Dr. Hema Siriwardane and Dr. Fernando Lima for agreeing to serve on my committee and helping me throughout the process.

I would like to thank all my fellow lab members from our research group. I thank Vikas Agarwal for his help with the wellbore model. I'd also like to thank Madhur Bedre and Xiaoning He for their help.

I'd like to thank all of the Cornell and Iowa State students who I have worked with. I thank Don Fox for his advice on running reservoir simulations in TOUGH2. I'd also like to thank Maciej Lukawski and Koenraad Beckers for their help on various topics regarding my research.

I would like to thank everyone at AltaRock Energy for the data they have provided our research group. Finally, I would like to thank my parents, Pete and Carol Peluchette, and my sister, Hayley Peluchette, for their love and support throughout my entire life. Without them, I would not be where I am today.

Thanks to everyone, Jason Peluchette 


\section{CONTENTS}

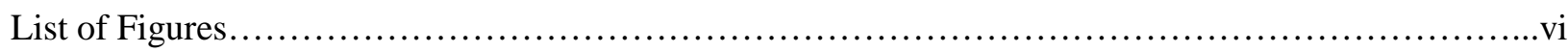

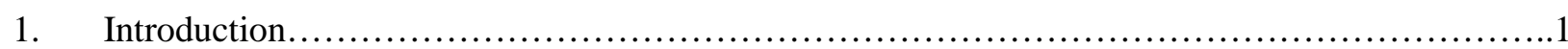

1.1 Geothermal energy and the potential of Enhanced Geothermal Systems (EGS)...............1

1.2 Motivation for this study............................................................

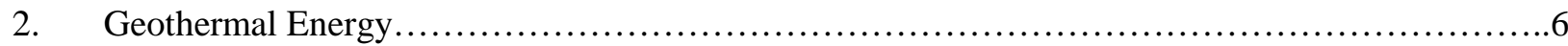

2.1 AltaRock Energy EGS Demonstration Project.......................................

2.2 EGS subsurface engineering and modeling.............................................

2.2.1 Wellbore model............................................................

2.2.2 Reservoir modeling with TOUGH2 and PetraSim...............................

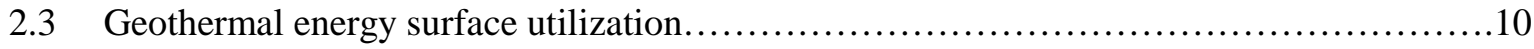

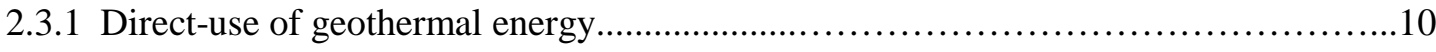

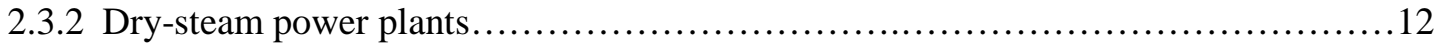

2.3.3 Flash-steam power plants.................................................

2.3.4 Binary cycle power plants.............................................. 15

3. Optimization of an Enhanced Geothermal System........................................16

3.1 Scope of the study .............................................................

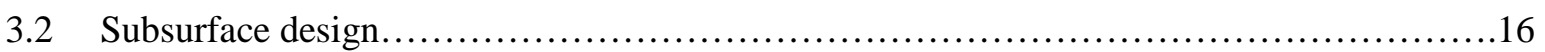

3.2.1 Wellbore design...............................................................16

3.2.2 Wellbore model predictions.................................................18

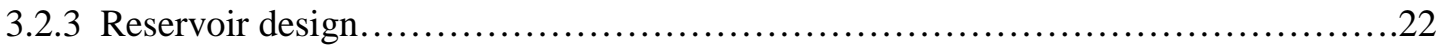

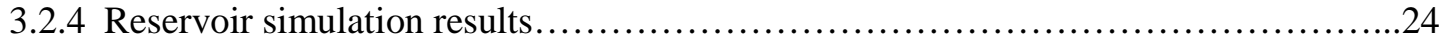

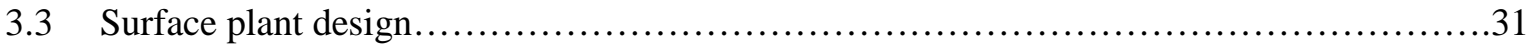

3.3.1 Topological surface plant optimization..........................................

3.3.2 Parametric optimization of the double-flash steam power plant....................33

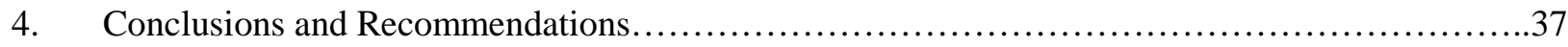




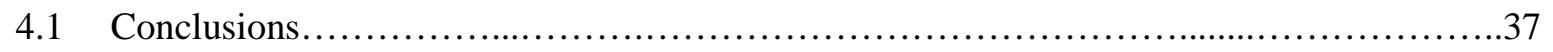

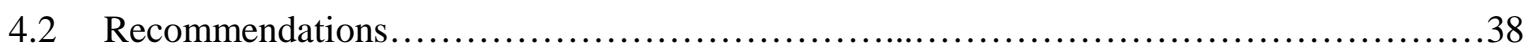

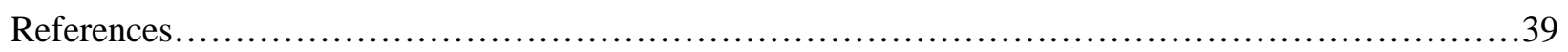




\section{LIST OF FIGURES}

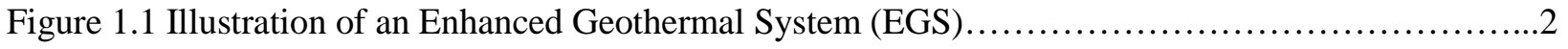

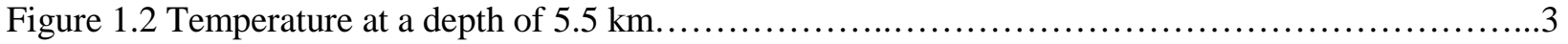

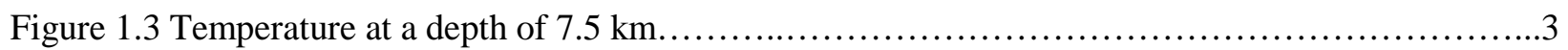

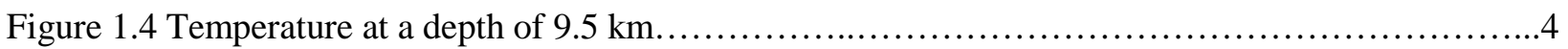

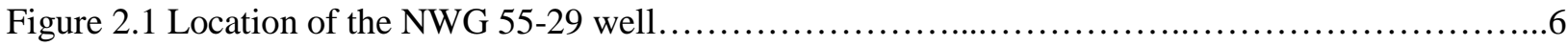

Figure 2.2 Direct-use applications for low-temperature geothermal fluids $\ldots \ldots \ldots \ldots \ldots \ldots \ldots \ldots \ldots \ldots \ldots 11$

Figure 2.3 Simplified diagram of a dry-steam geothermal power plant..............................12

Figure 2.4 The Geysers geothermal power plant in Geysers, California..............................

Figure 2.5 Basic schematic for single-flash geothermal power plant................................

Figure 2.6 Schematic of a binary cycle geothermal power plant...................................

Figure 3.1 Linear approximation of the geothermal gradient for NWG 55-29 well......................17

Figure 3.2 NWG 55-29 wellbore and casing profile...........................................

Figure 3.3 The wellbore fluid temperature with respect to well depth for a variety of injection

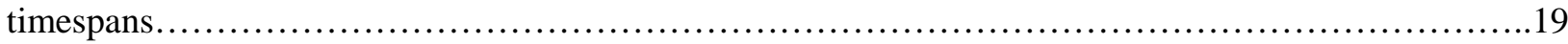

Figure 3.4 Bottom-hole injection temperature, or reservoir injection temperature, with respect to

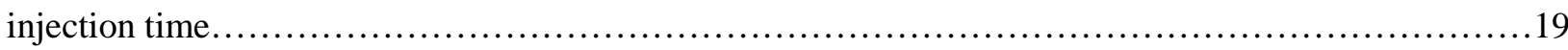

Figure 3.5 The change of pressure during injection predicted by the wellbore model..................20

Figure 3.6 Production temperature with respect to production time assuming a bottom-hole

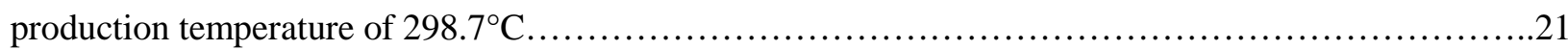

Figure 3.7 Pressure drop in the production well predicted by the wellbore model.....................21

Figure 3.8 Visualization from PetraSim of the base case design......................................

Figure 3.9 Change in reservoir temperature after 1 year of production for $50-\mathrm{m}$ spacing................24

Figure 3.10 Change in reservoir temperature after 10 years of production for 50 -m spacing............24

Figure 3.11 Change in reservoir temperature after 20 years of production for 50 -m spacing............25 
Figure 3.12 Change in reservoir temperature after 30 years of production for 50 -m spacing. .25

Figure 3.13 Comparison of the temperature change with time for the interior fracture and the two outside fractures .26

Figure 3.14 Change in reservoir temperature after 1 year of production for $100-\mathrm{m}$ spacing..............27

Figure 3.15 Change in reservoir temperature after 10 years of production for 100 -m spacing............27

Figure 3.16 Change in reservoir temperature after 20 years of production for $100-\mathrm{m}$ spacing.............27

Figure 3.17 Change in reservoir temperature after 30 years of production for 100 -m spacing.............28

Figure 3.18 Change in reservoir temperature after 1 year of production for the five-fracture system with $100-\mathrm{m}$ spacing.

Figure 3.19 Change in reservoir temperature after 10 years of production for the five-fracture system with 100 -m spacing.....

Figure 3.20 Change in reservoir temperature after 20 years of production for the five-fracture system with $100-\mathrm{m}$ spacing.

Figure 3.21 Change in reservoir temperature after 30 years of production for the five-fracture system with $100-\mathrm{m}$ spacing.

Figure 3.22 Comparison of the decrease in production temperature with respect to reservoir stimulation time for all three fracture networks that were investigated..... .30

Figure 3.23 Single-flash power plant optimization for a constant production fluid temperature of $298^{\circ} \mathrm{C}$

Figure 3.24 Double-flash power plant optimization for a constant production fluid temperature of $298^{\circ} \mathrm{C}$

Figure 3.25 The production temperature as a function of time that will be used for the optimization of the surface plant. .34

Figure 3.26 The NPV of electricity generated from the steam turbines at varying separator temperatures. 


\section{INTRODUCTION}

\subsection{Geothermal energy and the potential of Enhanced Geothermal Systems (EGS)}

There are valid concerns regarding the long term energy security of the United States due to the rapidly growing energy demand of our society. While it is understood that there are currently immense reserves of fossil fuels, there is a finite supply which must be taken into consideration when planning the energy infrastructure of the future. This is one reason to continue the development and implementation of renewable energy resources such as hydroelectric, solar, wind, and geothermal energy. Presently, all of these renewable energy resources have limitations that prevent them from being a major contributor to the energy supply. There are environmental concerns associated with hydropower, and solar and wind power battle reliability and efficiency issues. Geothermal energy has largely relied upon rare geologic regions containing the presence of hydrothermal reservoirs, thus limiting its contribution. However, recent breakthroughs in reservoir stimulation technology provide hope that the untapped potential of geothermal energy can be utilized in the coming decades.

With the vast amount of thermal energy available beneath the earth's surface, much research is being committed to improving the economic and technological feasibilities of Enhanced/Engineered Geothermal Systems (EGS). EGS are of interest because they can be implemented in low permeability areas that lack a natural hydrothermal resource. The current state of the art results in fractures that are located and spaced wherever nature has provided existing fractures. The hope is to take technology from shale production and apply to Enhanced Geothermal Systems to truly engineer the subsurface system. In these systems, cold water is injected into the hot, dry rock in order to increase the permeability and achieve higher transmissivity. With adequate connectivity and residence time, heated fluid can be transported from the engineered reservoir to the surface via a production well. Achieving adequate flow rate and connectivity in the reservoir are obstacles that have proven difficult to overcome in field research thus far.

The use of the heated water at the surface is dependent on the resource temperature. Typically, electricity is generated at a surface power plant when the fluid temperature exceeds $150^{\circ} \mathrm{C}$. Lower temperature reservoirs (less than $150^{\circ} \mathrm{C}$ ) provide a variety of options for direct-use applications, such as space heating, pool, pool heating, and various agricultural applications [He and Anderson, 2013], [Beckers, et al., 2013], [Tiarks, et al., 2013]. An illustration of an Enhanced Geothermal System is provided in Figure 1.1 


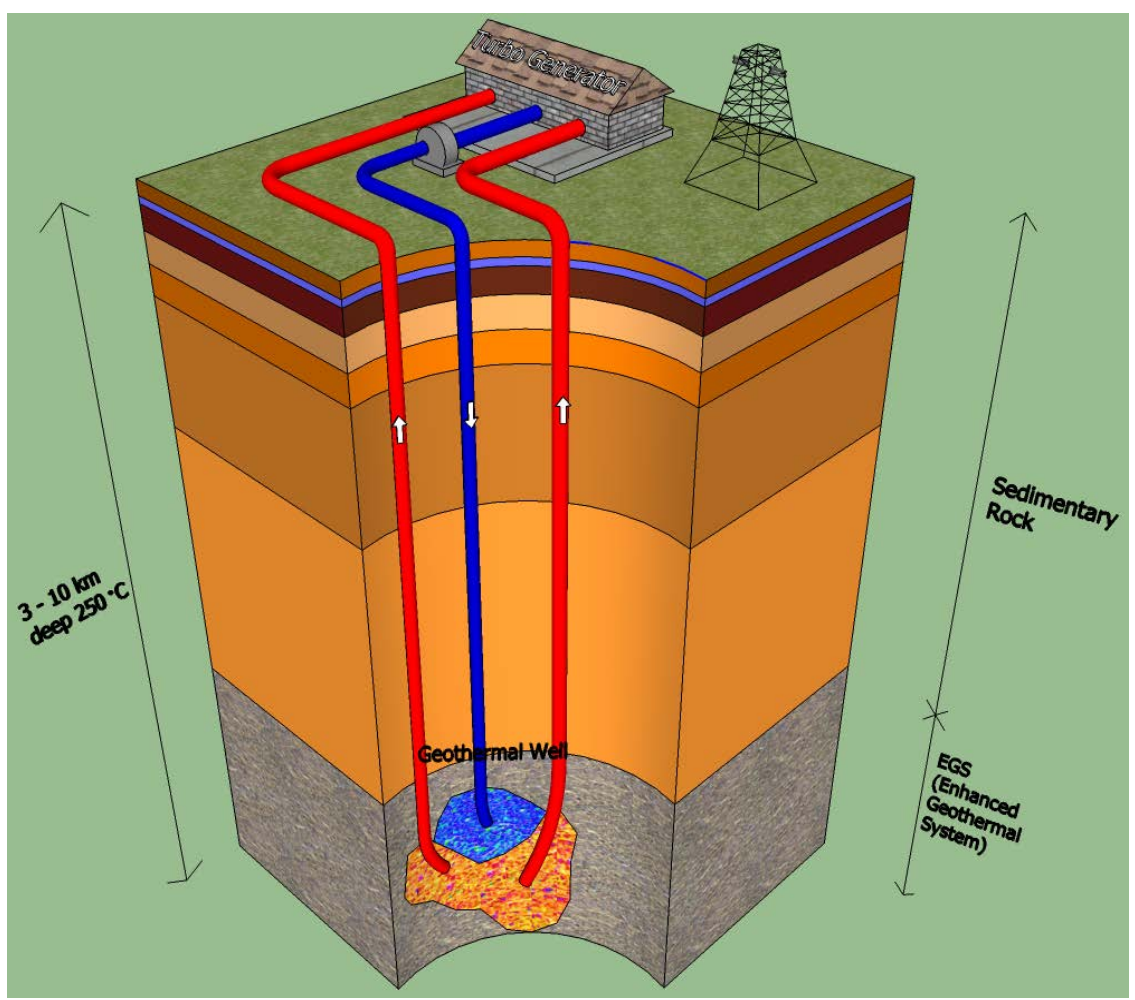

Figure 1.1 Illustration of an Enhanced Geothermal System (EGS)

Theoretically, Enhanced Geothermal Systems have no geographic limitations. However, due to high drilling costs, the economics suggest that areas with a high temperature-depth relationship (i.e. geothermal gradient) are preferred. Well drilling can constitute up to $60 \%$ of the total capital investment in areas with a low geothermal gradient. This value may decrease to around $30 \%$ in areas with a high geothermal gradient [Tester, et al., 2006]. This exorbitant up-front capital cost is expected to be less of a burden as drilling technology improves and more experience is gained from drilling future geothermal wells. The western U.S. has considerably greater heat flow yielding higher geothermal gradients. The maps in Figures 1.2-1.4 illustrate the U.S. geothermal resource at depths of 5.5 km, 7.5 km, and 9.5 km, respectively. 


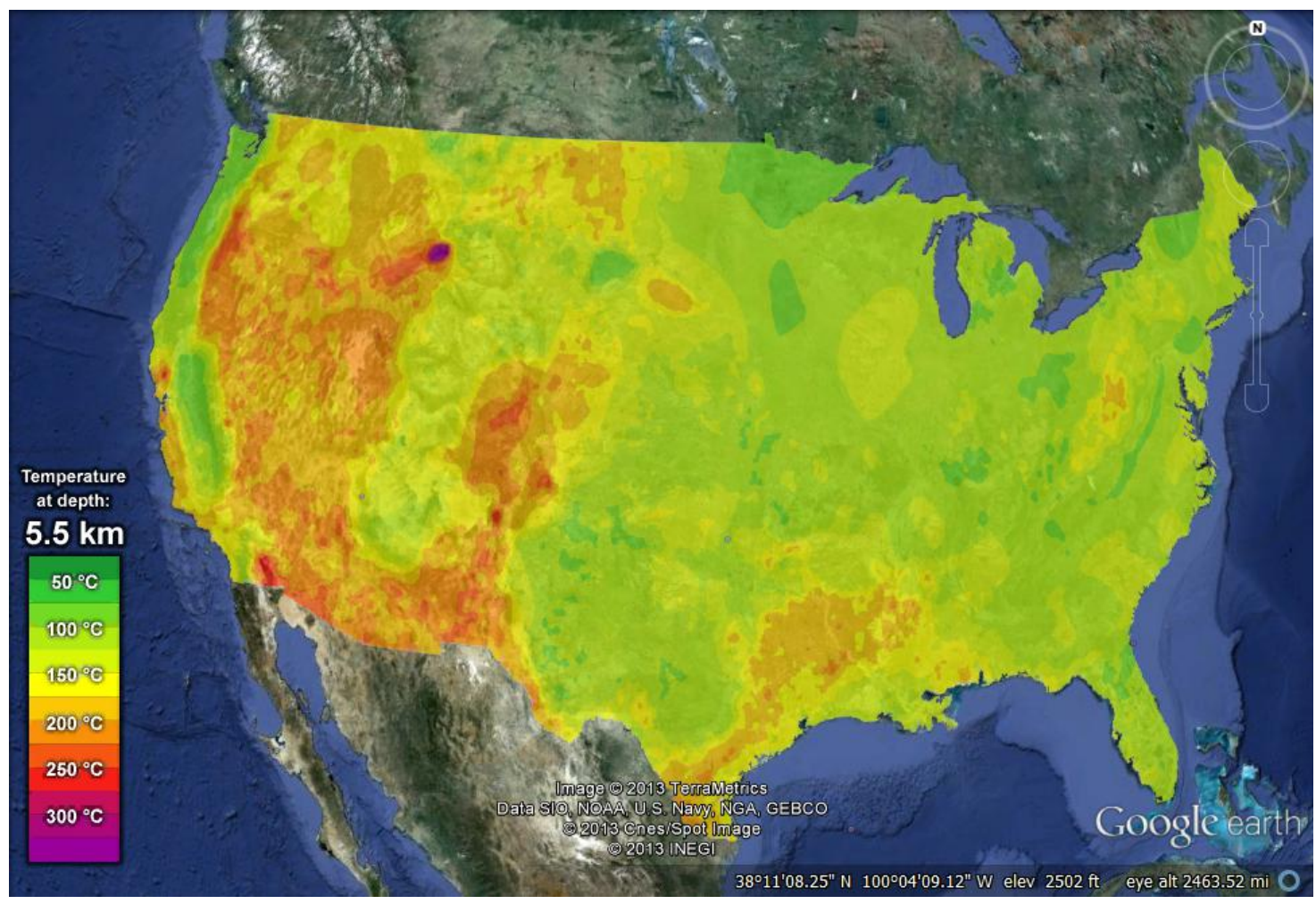

Figure 1.2 Temperature at a depth of 5.5 km [Google earth]

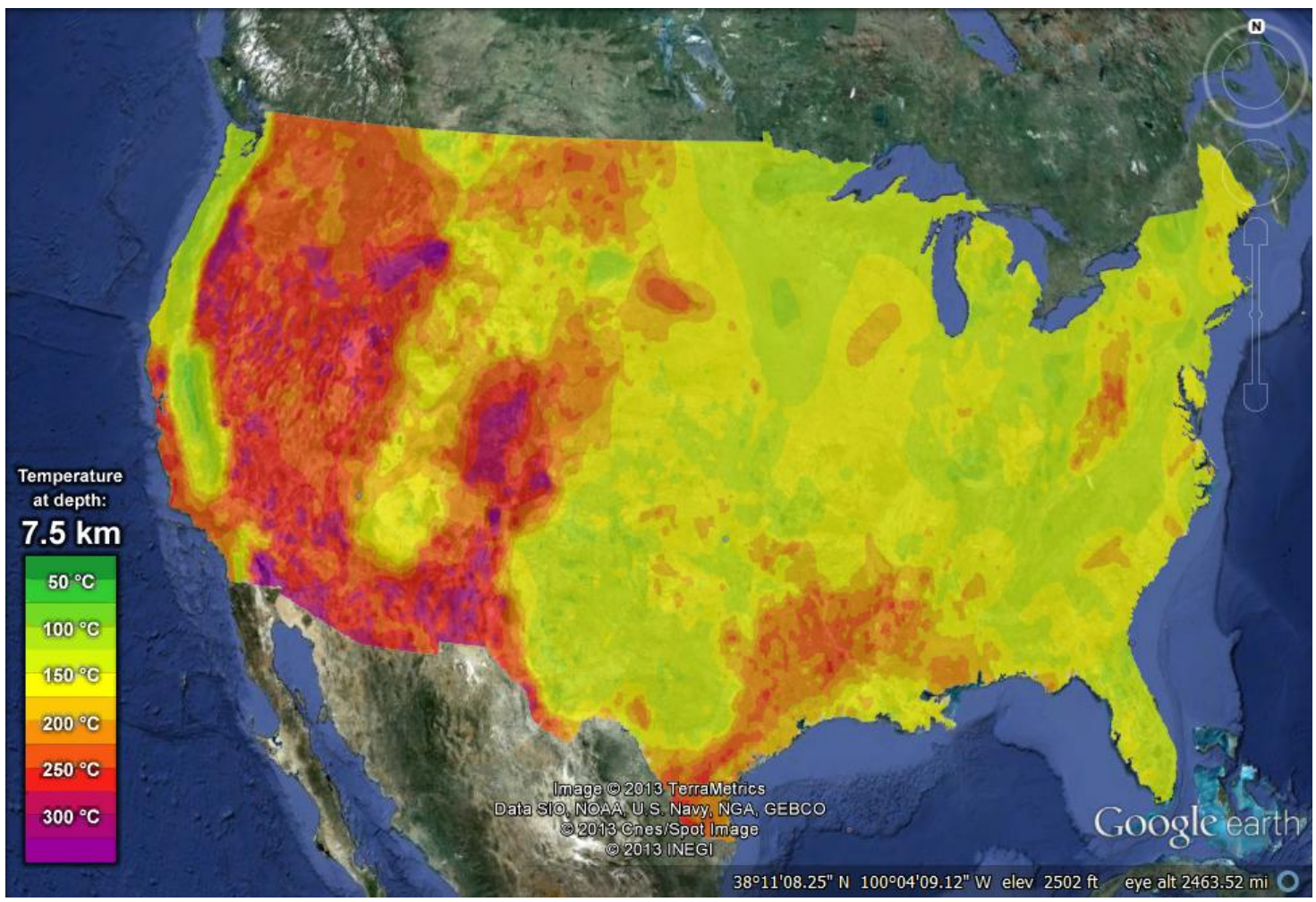

Figure 1.3 Temperature at a depth of 7.5 km [Google Earth] 


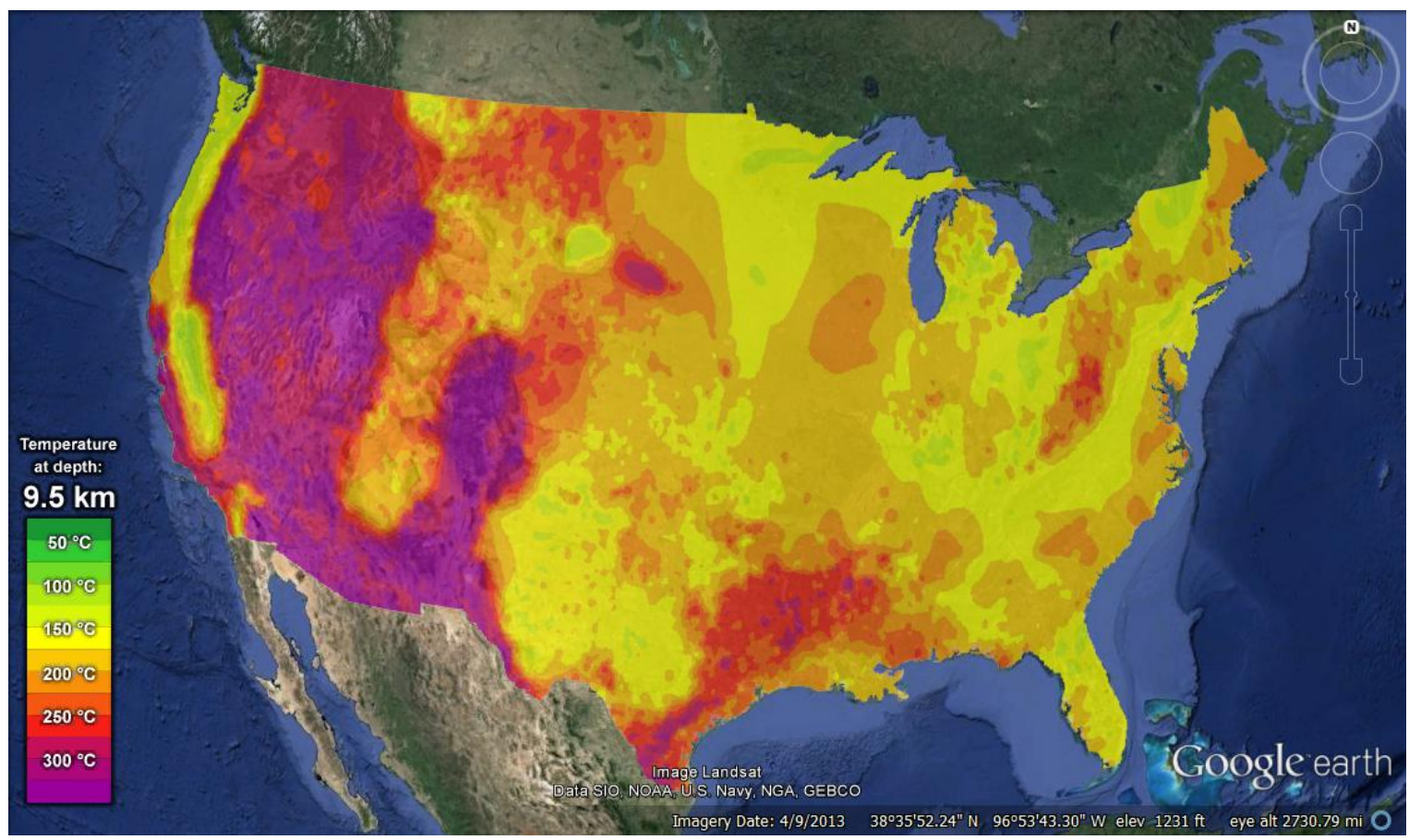

Figure 1.4 Temperature at a depth of $9.5 \mathrm{~km}$ [Google Earth]

In the last few decades, there has been substantial effort put forth to decrease the amount of greenhouse gas emissions in the U.S. Coal-fired power plants have been largely responsible for toxic emissions. Recent advancements in natural gas extraction techniques have resulted in increased estimates of recoverable natural gas reserves. Although natural gas is a substantially cleaner fuel than coal, combustion of methane still results in the emission of carbon dioxide $\left(\mathrm{CO}_{2}\right)$. In a geothermal power system, thermal energy is extracted from geologic sediment as opposed to burning fossil fuels. Electrical power generation from geothermal energy results in little to no greenhouse gas emissions. A closed-loop EGS that contains no non-condensable gases would emit no $\mathrm{CO}_{2}$. A comparison of gaseous emissions from various power sources is presented in Table 1.1.

Table 1.1 Gaseous emissions from different power sources [Kagel, et al., 2005], [Tester, et al., 2006]

\begin{tabular}{|l|l|l|l|l|}
\hline Plant type & $\begin{array}{l}\mathrm{CO}_{2} \\
(\mathrm{~kg} / \mathrm{MWh})\end{array}$ & $\begin{array}{l}\mathrm{SO}_{2} \\
(\mathrm{~kg} / \mathrm{MWh})\end{array}$ & $\begin{array}{l}\mathrm{NO}_{\mathrm{x}} \\
(\mathrm{kg} / \mathrm{MWh})\end{array}$ & $\begin{array}{l}\text { Particulates } \\
(\mathrm{kg} / \mathrm{MWh})\end{array}$ \\
\hline Coal-fired & 994 & 4.71 & 1.955 & 1.012 \\
\hline Oil-fired & 758 & 5.44 & 1.814 & N/A \\
\hline Gas-fired & 550 & 0.0998 & 1.343 & 0.0635 \\
\hline Geothermal - flash-steam & 27.2 & 0.1588 & 0 & 0 \\
\hline Geothermal - The Geysers dry-steam field & 40.3 & 0.000098 & 0.000458 & Negligible \\
\hline Geothermal - binary cycle & 0 & 0 & 0 & Negligible \\
\hline EPA average - all U.S. plants & 631.6 & 2.734 & 1.343 & N/A \\
\hline
\end{tabular}


The data provided in Table 1.1 exhibit the dramatically lower gaseous emissions from geothermal power plants in comparison to fossil fuel based power plants.

There are several compelling reasons to be optimistic about the future growth of geothermal energy. With the progression of Enhanced Geothermal Systems, there is enormous potential for geothermal energy to contribute to the future U.S. energy markets. There are also distinct environmental advantages to utilizing geothermal energy. The Future of Geothermal Energy, an evaluation of the technical and economic viability of EGS, best describes its potential by concluding, “To sum up, based on our technical and economic analysis, a reasonable investment in $\mathrm{R} \& \mathrm{D}$ and a proactive level of deployment in the next 10 years could make EGS a major player in supplying 10\% of U.S. baseload electricity by 2050.” [Tester, et al., 2006]

\subsection{Motivation for this study}

This study presents an optimization of a water-based Enhanced Geothermal System (EGS) modeled for AltaRock Energy's Newberry EGS Demonstration location. The optimization successfully integrates all three components of the geothermal system: (1) the present wellbore design, (2) the reservoir design, and (3) the surface plant design. Prior to this study, an optimization that incorporates all three of these components of an Enhanced Geothermal System has not been done. This was the primary motivation behind this study. Since the Newberry EGS Demonstration will use an existing well (NWG 55-29), there is no optimization of the wellbore design, and the aim of the study for this component is to replicate the present wellbore conditions and design. For the reservoir design, the existing conditions, such as temperature and pressure at depth and rock density, are incorporated into the model, and several design variables are investigated. Also, different power plant designs are explored, and the system optimization requires the investigation of surface plant design parameters. The ultimate goal is to determine the optimal surface plant operating conditions and reservoir design for the implementation of an EGS at the Newberry site. This study provides a comparison for future comprehensive EGS optimizations.

This study was completed in collaboration with AltaRock Energy. AltaRock's goal is to create an EGS reservoir at the Newberry site and ultimately run a circulation test with production from the EGS reservoir. The purpose of the Newberry EGS project is to demonstrate their EGS technology and the potential growth for EGS in the future. They provided our research group with valuable information, and the hope is that this research assists their design and research efforts in any possible manner. 


\section{GEOTHERMAL ENERGY}

\subsection{AltaRock Energy EGS Demonstration Project}

Economic feasibility has hampered the commercial implementation of Enhanced Geothermal Systems (EGS); however, AltaRock Energy is developing methods to advance EGS stimulation technology. AltaRock is a geothermal energy research company headquartered out of Seattle, Washington, whose primary focus is the development of EGS stimulation technology. The DOE awarded AltaRock and Davenport Newberry \$21.45 million for the Newberry EGS Demonstration. According to Susan Petty, the President and Chief Technology Officer of AltaRock, this award is the largest grant awarded by the Department of Energy's Geothermal Technologies Program, and it reflects the DOE's confidence in the project. The existing Northwest Geothermal (NWG) 55-29 well in Newberry, Oregon, is the site of the project. A map displaying this well location is provided in Figure 2.1.

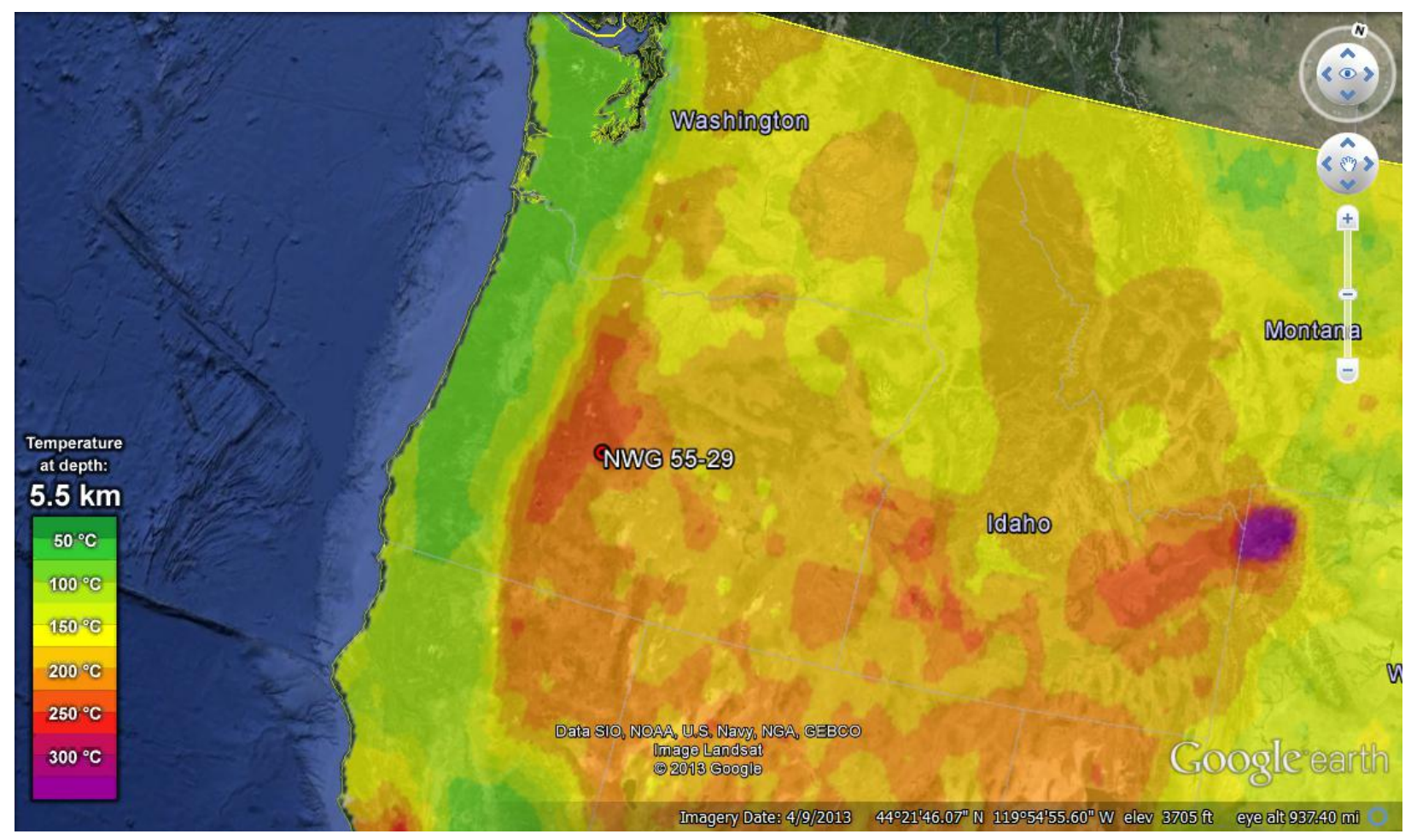

Figure 2.1 Location of the NWG 55-29 well [Google Earth]

This is an ideal location for the demonstration of the technology for two reasons: (1) the existing well does not require any modifications and (2) the bottom-hole temperature is in excess of $300^{\circ} \mathrm{C}$. This project provides AltaRock with the opportunity to demonstrate their EGS stimulation technology, while also creating an EGS reservoir, with the ultimate goal of developing a conceptual model for a full 
Enhanced Geothermal System [Petty, 2010]. AltaRock has already been successful in demonstrating the stimulation technology by successfully injecting into multiple zones at different depths. The next step is to create an EGS reservoir with the NWG 55-29 well as the injection well. The final step is to have two production wells drilled in order to connect the EGS reservoir. This will allow AltaRock to run a three month circulation test [Cladouhos, 2011]. The Newberry EGS Demonstration will also provide a model for future EGS of similar characteristics.

\subsection{EGS subsurface engineering and modeling}

\subsubsection{Wellbore model}

In order to jointly optimize the subsurface and surface system, it is necessary to model the pressure and temperature changes in the wellbore during injection and production. This will be accomplished by using an in-house wellbore model that was created by Vikas Agarwal in Microsoft Excel and is programmed with Microsoft Visual Basic [Agarwal, 2010].

Equations 2.1-2.7 lay the groundwork for determining the pressure and temperature changes for any wellbore design. These equations are programmed into the wellbore model. The entire wellbore is discretized into small portions that are $10 \mathrm{~m}$ in height. The properties within this $10 \mathrm{~m}$ portion are constant with respect to height, $z$. For the injection well calculations, the wellhead conditions are known values and used to determine the temperature, pressure, and fluid properties at any given depth in the well. The ultimate purpose of the injection portion of the wellbore model is to determine the temperature and pressure of the fluid at the bottom-hole depth where injection into the EGS reservoir occurs. The bottom-hole injection conditions are necessary in order to complete the reservoir modeling. The production well is modeled in the same manner with only the initial conditions reversed. In this case, the results from the reservoir modeling are used as the initial known values for the discretization of the production well from the reservoir to the surface plant. The ultimate purpose of the production well portion of the wellbore model is to determine the fluid temperature and pressure at the surface. It is necessary to know the fluid conditions upon entrance to the surface plant in order to properly design the surface plant and optimize the system.

The fluid pressure at a given depth can be determined from the Navier-Stokes momentum equation. This relationship is:

$$
\frac{d P}{d z}+\rho v \frac{d v}{d z}+\rho g+f \frac{\rho v^{2}}{2 d}=0
$$


where $P$ represents the fluid pressure, $z$ represents the vertical distance, $\rho$ represents the fluid density, $v$ represents the velocity in the $z$-direction, $g$ represents the acceleration due to gravity, $f$ represents the friction factor, and $d$ represents the wellbore diameter. Neglecting the acceleration term $\left(\rho v \frac{d v}{d z}\right)$ yields this:

$$
\frac{d P}{d z}+\rho g+f \frac{\rho v^{2}}{2 d}=0
$$

The friction factor, $f$, can be determined here:

$$
\frac{f^{2}}{2}=-\log \left\{\frac{\epsilon / d}{3.7065}-\frac{5.045}{\operatorname{Re}} \log \left(\frac{\epsilon / d^{1.1098}}{2.8257}+\left(\frac{7.149}{\operatorname{Re}}\right)^{0.898}\right)\right\}
$$

In Equation 2.3, $\varepsilon$ is the pipe roughness, and Re is the Reynolds number shown here:

$$
\operatorname{Re}=\frac{\rho d v}{\mu}
$$

where $\mu$ represents the fluid viscosity.

Along with the pressure, the temperature of the fluid, $T_{f}$, must also be determined with respect to depth. An energy balance allows for the derivation of the temperature. The energy balance is:

$$
\frac{d h}{d z}+g+v \frac{d v}{d z}=\frac{Q}{\dot{m}}
$$

where $h$ is the enthalpy per unit mass, $Q$ is the heat flow rate per unit length, and $m$ ' is the mass flow rate. The heat transfer equation relates the heat flow, $Q$, to the fluid temperature, $T_{f}$, and this relationship is:

$$
Q=2 \pi r_{c} U_{c}\left(T_{f}-T_{w b}\right)
$$

In Equation 2.6, $r_{c}$ is the radius of the casing, $U_{c}$ is the overall heat transfer coefficient, and $T_{w b}$ is the temperature at the wellbore-earth interface. In order to accurately model the wellbore temperature, temperature diffusivity with respect to time must be accounted for. This relationship is:

$$
\frac{\partial^{2} T_{e}}{\partial r^{2}}+\frac{1}{r} \frac{\partial T_{e}}{\partial r}=\frac{c_{e} \rho_{e}}{k_{e}} \frac{\partial T_{e}}{\partial t}
$$

where $c_{e}, \rho_{e}$, and $k_{e}$ are the rock properties heat capacity, density, and thermal conductivity, respectively. The derivation of Equation 2.7 for temperature is solved in Fluid Flow and Heat Transfer in Wellbores [Hasan and Kabir, 2002]. This derivation utilizes Laplace transforms and yields an equation for the dimensionless temperature, $T_{D}$, which is dependent on dimensionless time, $t_{D}$. The result of this derivation is: 


$$
T_{D}=\ln \left[e^{-0.2 t_{D}}+\left(1.5-0.3719 e^{-t_{D}}\right) \sqrt{t_{D}}\right]
$$

where $T_{D}$ is defined as:

$$
T_{D} \equiv-\frac{2 \pi k_{e}}{Q}\left(T_{w b}-T_{e i}\right)
$$

In Equation 2.9, $T_{e i}$ represents the initial temperature of the earth as a function of depth. Dimensionless time, $t_{D}$, is determined by this relationship:

$$
t_{D}=\frac{\alpha t}{r_{w b}^{2}}
$$

where $\alpha$ is the thermal diffusivity $\left(\frac{k_{e}}{c_{e} \rho_{e}}\right)$ and $r_{w b}$ is the outer radius of the cement.

There are four primary assumptions in the wellbore model: (1) no variation of temperature, pressure, and fluid velocity in the radial direction of the well since the diameter of the well is orders of magnitude smaller than the length, (2) the thermal gradient of the earth is assumed constant $\left(95^{\circ} \mathrm{C} / \mathrm{km}\right.$ for this design), (3) the acceleration term in the energy balance (Equation 2.1) is negligible because the change in velocity is insignificant compared to the pressure gradient, and (4) since the fluid velocity is high, vertical heat diffusion is considered negligible in comparison to the convective heat transfer.

\subsubsection{Reservoir modeling with TOUGH2 and PetraSim}

The simulations of the reservoir will be modeled using TOUGH2. TOUGH2 is a numerical simulator for nonisothermal fluid flow through fractured porous media and stands for the Transport Of Unsaturated Groundwater and Heat. It simulates the flow of a fluid in the fractured media while also predicting the temperature and pressure of the fluid and the surrounding rock [Pruess, et al., 1999]. The simulator allows the user to create the desired reservoir and fracture network, inject fluid into the reservoir, then simulate the reservoir behavior for the desired timespan. TOUGH2 is coupled with the graphical interface PetraSim. The simulation program is written in standard FORTRAN77 and was developed at the Lawrence Berkeley National Laboratory. 


\subsection{Geothermal energy surface utilization}

\subsubsection{Direct-use of geothermal energy}

When there is a low-temperature geothermal resource available (typically considered less than $150^{\circ} \mathrm{C}$ ), it is often decided to use the geothermal fluid directly in a variety of applications as opposed to converting the thermal energy into electricity. The requirements for a direct-use system are a geothermal source (typically a well), a distribution system (piping, controllers), and a method of disposal (pond, river, or injection well). Since direct-use systems are typically implemented for low-temperature resources, there are no geographical limitations. There are a variety of uses depending on the temperature of the fluid. The primary uses are for district heating, space heating, and agricultural applications [Geothermal Technologies Program, 2013]. The Lindal Diagram shows potential direct-use applications for lowtemperature resources. This is provided in Figure 2.2. 


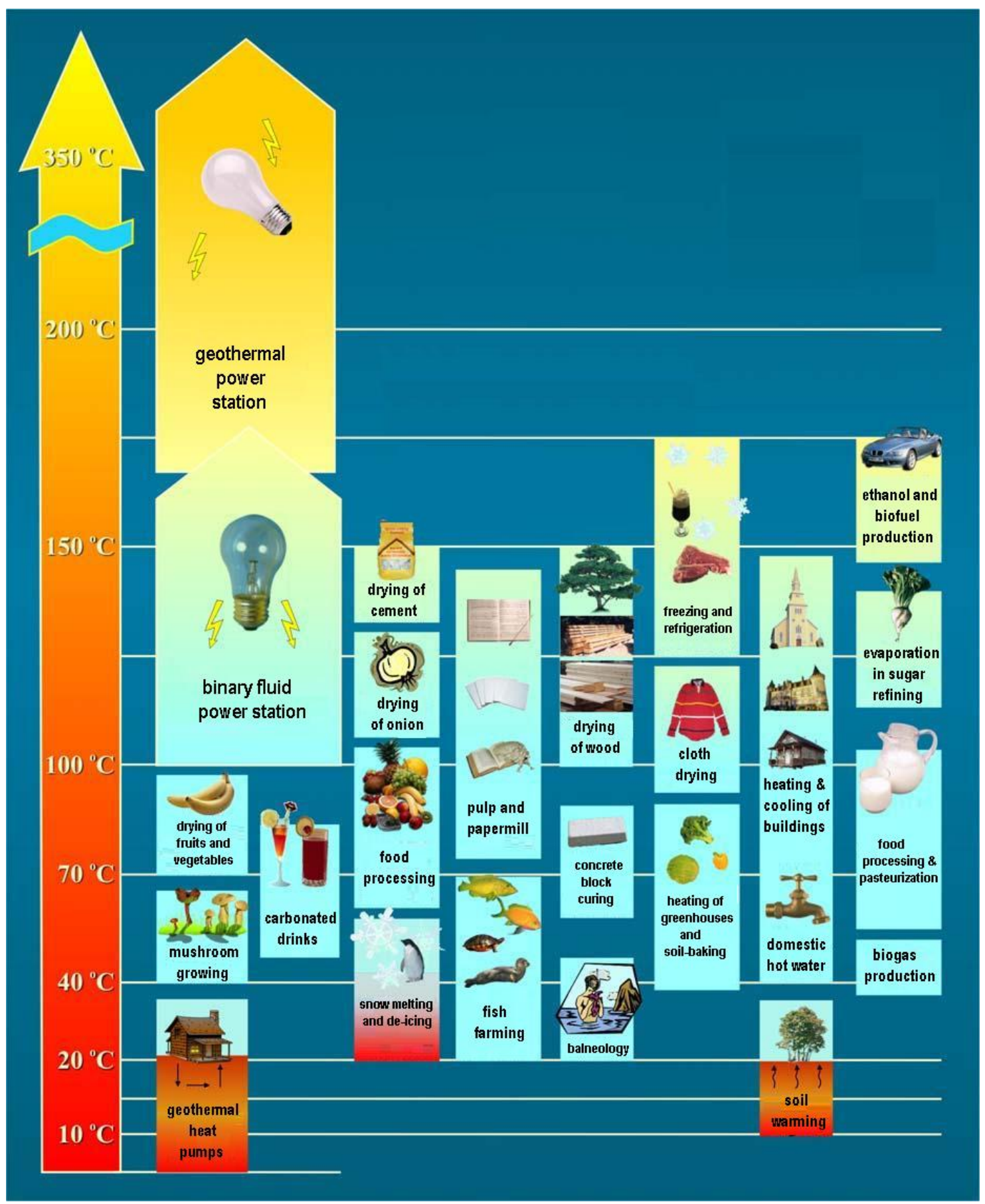

Figure 2.2 Direct-use applications for low-temperature geothermal fluids [College of Geothermal Professionals, 2011.]

As pointed out in the Lindal Diagram, there is the option of electricity generation or direct-use between the temperatures of $100^{\circ} \mathrm{C}$ and $180^{\circ} \mathrm{C}$.

The implementation of a direct-use geothermal system is inexpensive in comparison to traditional fossil fuels. The U.S. DOE Office of Energy Efficiency and Renewable Energy estimates that geothermal 
district heating systems can save $30-50 \%$ of the cost of using natural gas [Geothermal Technologies Program, 2013]. There are also substantially less harmful pollutants emitted from a geothermal system as opposed to a natural gas based system.

\subsubsection{Dry-steam power plants}

Dry-steam power plants were the first type of geothermal power plants to be commercially used. The first one was operated in Larderello, Italy in 1904. Dry-steam power plants are used in rare geologic locations where high quality steam is available near the surface. This is an ideal situation for the production of electricity from geothermal energy, as it is relatively simple to use a generator for electricity production with this resource available [DiPippo, 2008]. The steam resource from beneath the earth is harnessed and piped directly into the turbine which drives a generator for the production of electricity. An illustration of the operating procedure of a dry-steam power plant is provided in Figure 2.3.

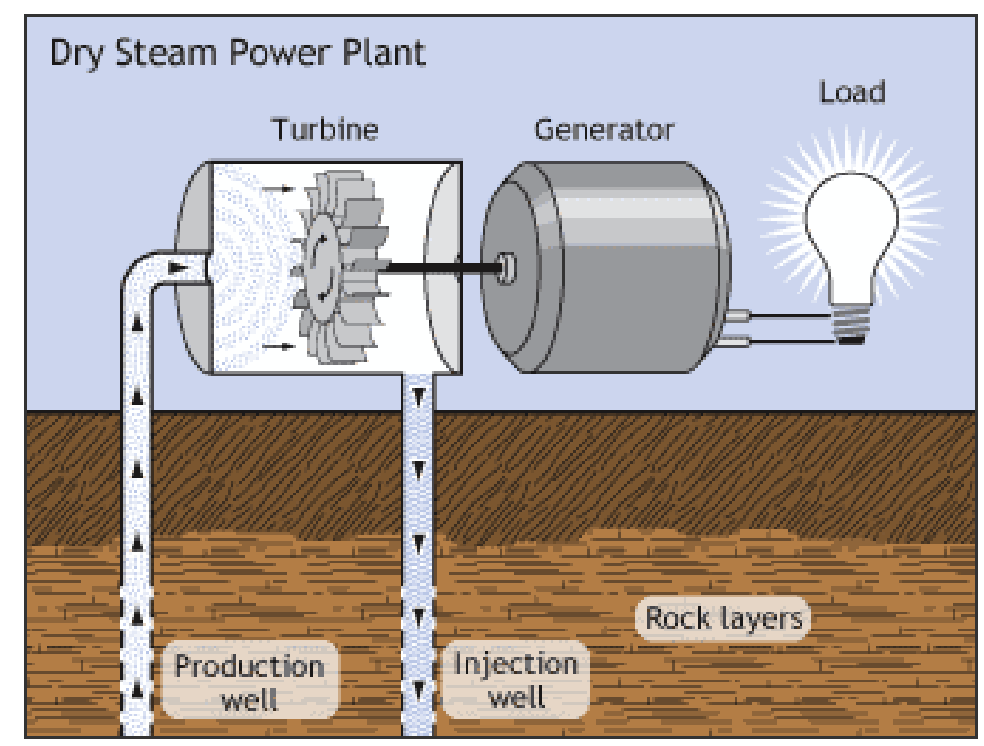

Figure 2.3 Simplified diagram of a dry-steam geothermal power plant [Geothermal Technologies Program, 2012]

The largest geothermal power plant complex in the world is The Geysers in northern California. The Geysers produces nearly $700 \mathrm{MW}_{\mathrm{e}}$ and accounts for roughly $60 \%$ of the electricity used between San Francisco and the California-Oregon state line [Calpine Corporation, 2012]. An image of The Geysers is provided in Figure 2.4. 


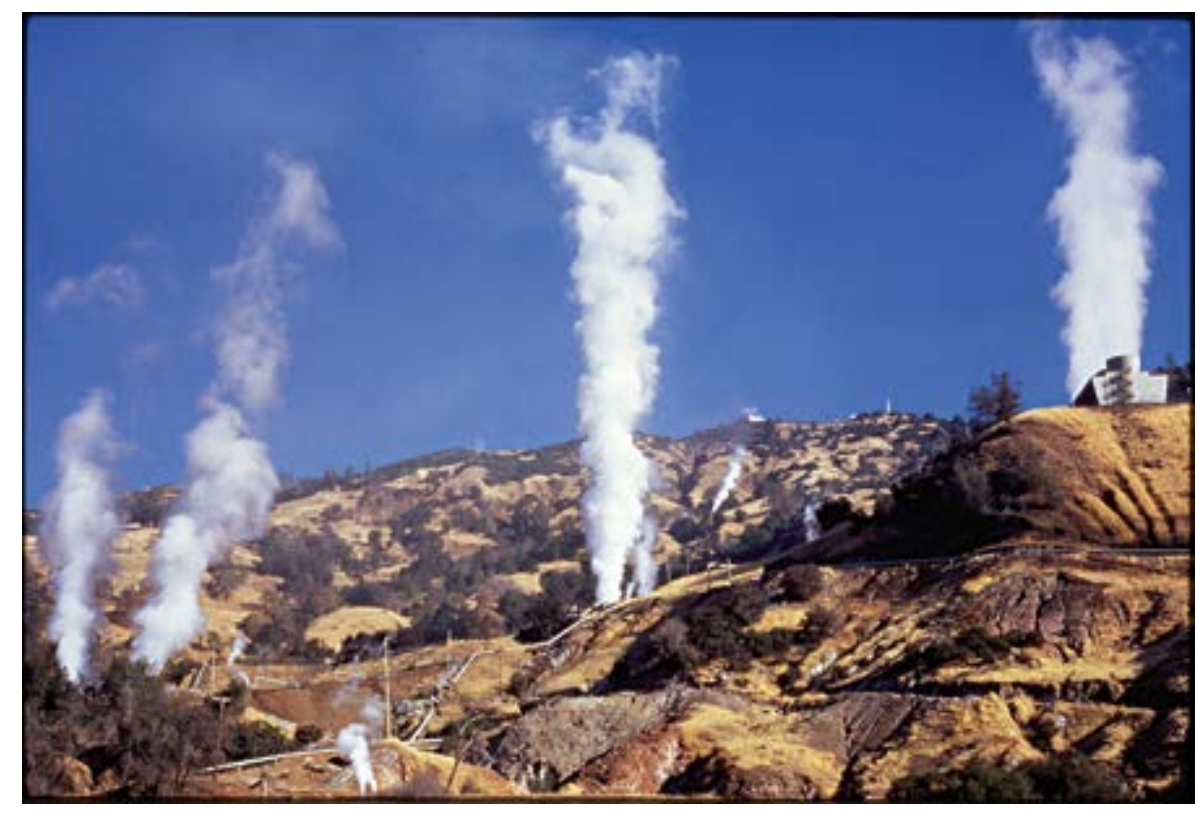

Figure 2.4 The Geysers geothermal power plant in Geysers, California [Calpine Corporation, 2012]

\subsubsection{Flash-steam power plants}

A flash-steam power plant is the most efficient way to produce electricity for a high-temperature liquid or liquid-gas mixture. There are primarily two types of flash-steam power plants that are used: (1) singleflash and (2) double-flash. A basic schematic of a single-flash power plant is provided in Figure 2.5. 


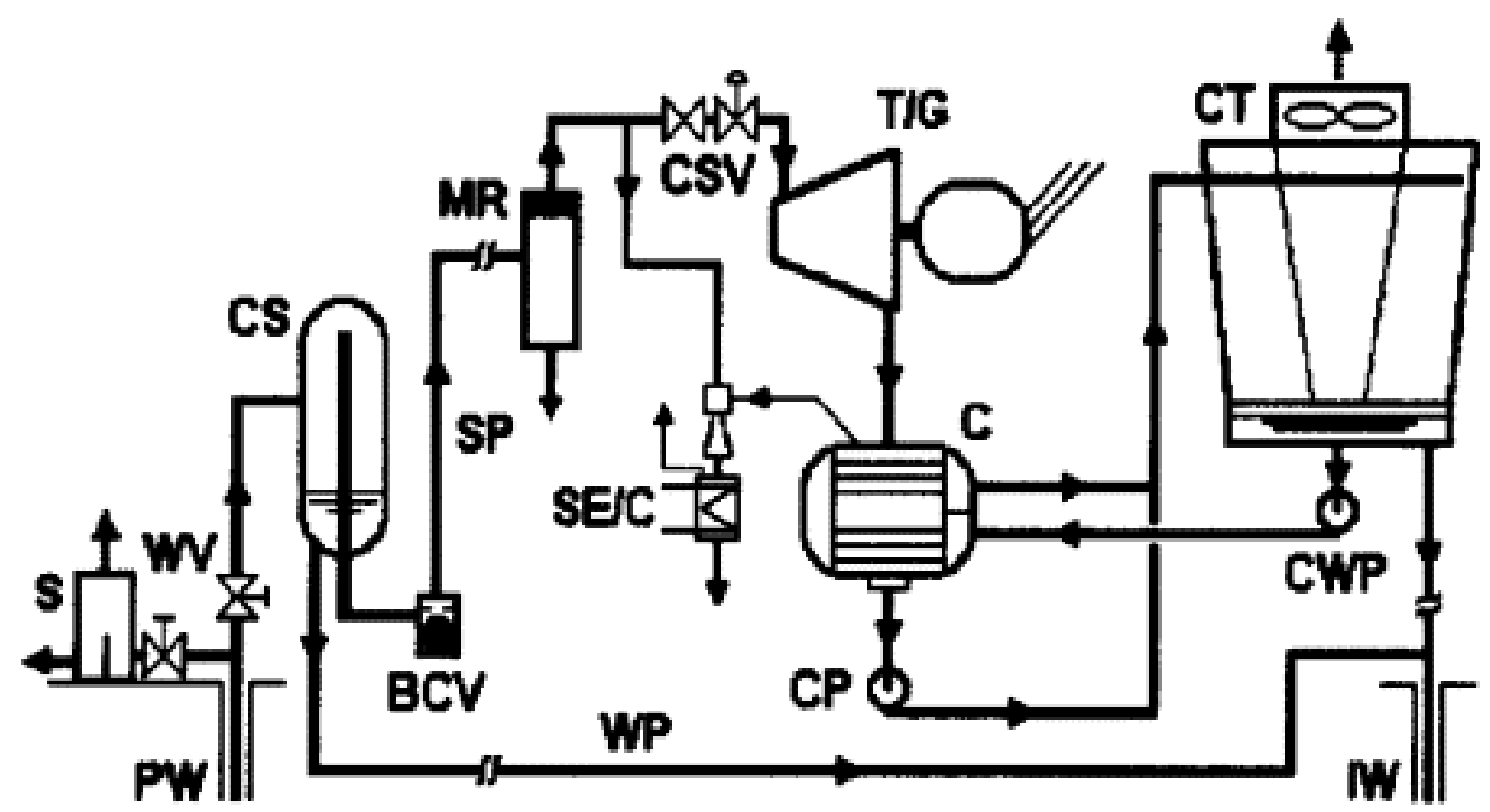

Figure 2.5 Basic schematic for single-flash geothermal power plant [DiPippo, 2008]

The compressed fluid exits the production well and enters a cyclone separator, CS. Upon entering the separator there is a reduction in pressure causing the fluid to flash. The steam travels through a moisture remover, MR, prior to entering the steam turbine to ensure that there is no liquid in the stream. The steam is used to drive the turbine which drives an electric generator. The steam leaves the turbine at a reduced pressure and temperature, assumed $50^{\circ} \mathrm{C}$ for this design. The steam enters the shell side of the condenser and is condensed by cooling water flowing through the tube side of the condenser. There is typically a steam jacket ejector, SE/C, which is used to remove non-condensable gases such as carbon dioxide. Finally, the condensed steam is sent through a cooling tower. The stream is then mixed with the liquid stream from the initial separation and pumped into the injection well at the reinjection pressure.

The double-flash steam power plant design is very similar with the only difference being the addition of a second separation. The liquid stream from the initial separation by the cyclone separator enters a flash vessel with the goal of recovering more steam and ultimately generating more power with the addition of a second turbine. The implementation of a double-flash system as opposed to a single-flash can result in a 15-25\% increase in power output [DiPippo, 2008]. Water usage is a concern in arid climates of the western U.S. Double-flash systems can lose up to $85 \%$ of the geothermal fluid. Therefore, binary systems may be more common than double-flash systems for EGS. 


\subsubsection{Binary cycle power plants}

Binary cycle power plants more closely resemble a traditional power plant than the other surface utilization options that have been discussed. In a binary cycle geothermal power plant, the geothermal fluid transfers thermal energy to the working fluid in a closed-loop system. These power plants are implemented when a low-temperature resource is available (less than $175^{\circ} \mathrm{C}$ ), yet the production of electricity is still desired. A flash-steam power plant is less efficient and more costly at lower temperature ranges. A binary cycle power plant follows the schematic provided in Figure 2.6.

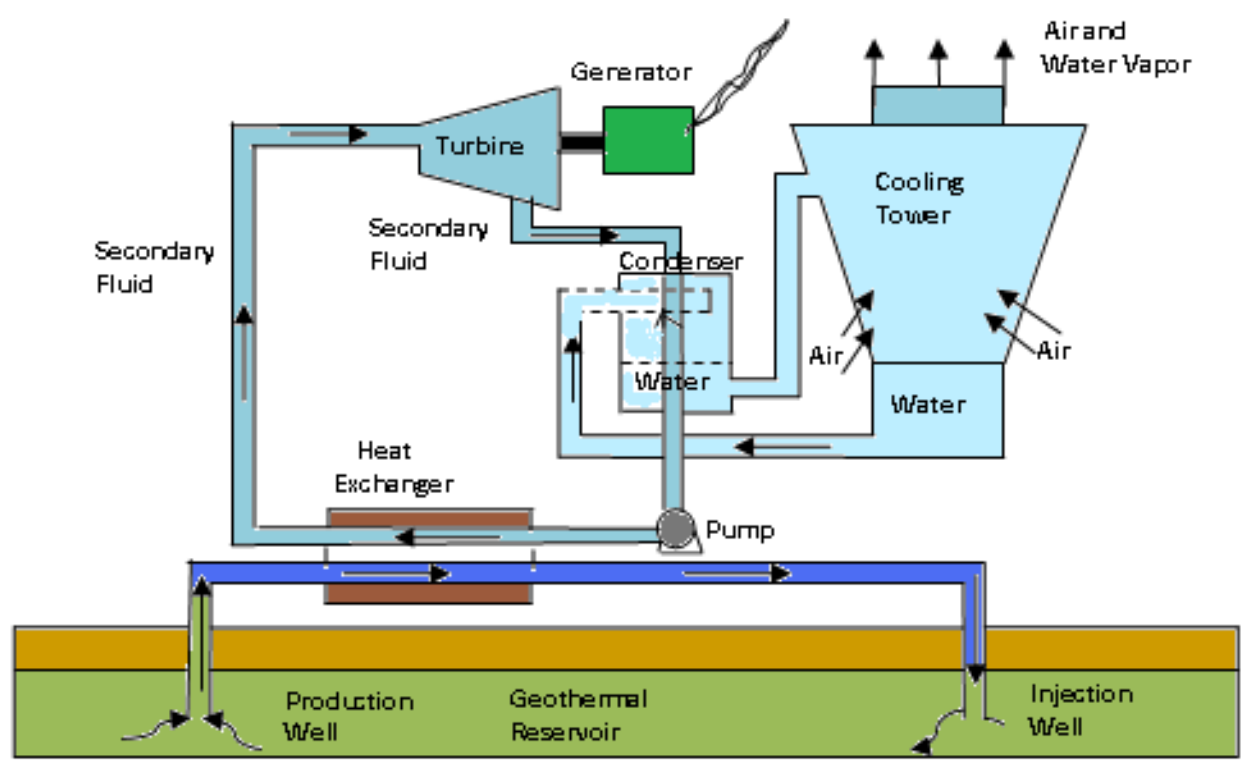

Figure 2.6 Schematic of a binary cycle geothermal power plant [Image courtesy of Vikas Agarwal]

In a binary cycle power plant, there are two primary fluids, the geothermal fluid and the working fluid. The geothermal fluid is extracted from the earth via the production well, and it is pumped through a heat exchanger where it transfers heat to the working fluid. The working fluid is chosen to have a significantly lower boiling point than the geothermal fluid with the intention of vaporizing the working fluid upon passing through the heat exchanger. The saturated vapor (working fluid) is used to drive a turbine which drives a generator, thus resulting in the production of electricity. A condenser with a cooling water loop is used to return the working fluid to its original state in preparation to re-enter the heat exchanger. The cooled geothermal fluid can be injected into the reservoir to recover more thermal energy. The geothermal fluid is to be kept at pressures above its flash point throughout the system in order to avoid scaling issues [DiPippo, 2008]. 


\section{OPTIMIZATION OF AN ENHANCED GEOTHERMAL SYSTEM}

\subsection{Scope of the study}

This study presents an optimization of a water-based Enhanced Geothermal System (EGS). The entire system optimization consists of two components: the subsurface and the surface plant design. The subsurface system is modeled using the reservoir simulator TOUGH2 coupled with the graphical interface PetraSim for visualization. Additionally, an in-house wellbore model is used to accurately reflect the temperature and pressure changes that occur in the wellbore fluid and the surrounding casing, cement, and earth during injection and production. Several design parameters are considered for the subsurface optimization, such as fluid mass flow rate and the design of the fracture system. The surface section involves the optimization of the surface plant for the production of electricity, where a topological and a parametric optimization are completed. Thus, this study determines which type of power plant is best suited for this geothermal system.

The conditions present at the Newberry, Oregon EGS project site are the basis for this optimization. The subsurface conditions are favorable for the production of electricity from geothermal energy with rock temperatures exceeding $300^{\circ} \mathrm{C}$ at a well depth of $3 \mathrm{~km}$. This research was completed in collaboration with AltaRock Energy, which has provided our research group with data from the Newberry well.

The purpose of this research is to determine the optimal conditions for operating an Enhanced Geothermal System for the production of electricity at Newberry.

\subsection{Subsurface design}

\subsubsection{Wellbore design}

The goal of the subsurface design is to accurately reflect the present conditions at the NWG 55-29 well at the site of the Newberry EGS Demonstration, while also investigating various optimization parameters in the engineered reservoir. The conditions at Newberry that are used in this research include (1) the geothermal gradient of $95^{\circ} \mathrm{C} / \mathrm{km}$ (linear approximation of the real data) to accurately reflect the geothermal resource potential at the bottom-hole depth, (2) the NWG 55-29 casing design for the wellbore model, (3) the known rock properties at the depth of the engineered reservoir, (4) the wellhead injection pressure of $15 \mathrm{MPa}$, and (5) the maximum achievable flow rate through a single fractured zone 
of $25 \mathrm{~kg} / \mathrm{s}$. The linear approximation of the geothermal gradient used in this study is provided in Figure 3.1.

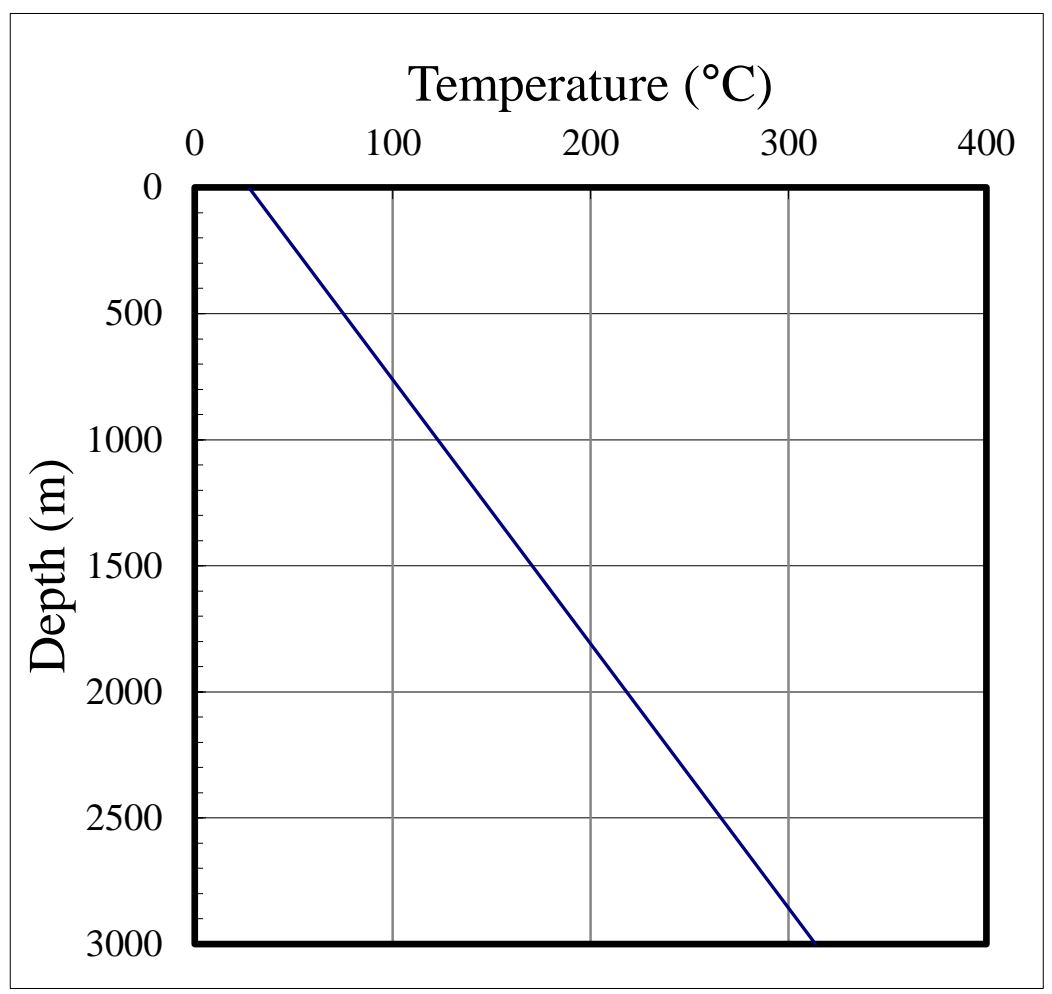

Figure 3.1 Linear approximation of the geothermal gradient for NWG 55-29 well

The geothermal gradient provided in Figure 3.1 has been implemented into the wellbore model to accurately predict the temperature effects in the injection and production wells.

The NWG 55-29 well extends to a bottom-hole depth of $3060 \mathrm{~m}$, and the casing design is provided in Figure 3.2. Also, the NWG 55-29 well approaches the bottom-hole depth at an angle of roughly $30^{\circ}$. This is accounted for in the reservoir modeling by rotating the gravity vector in the model. 


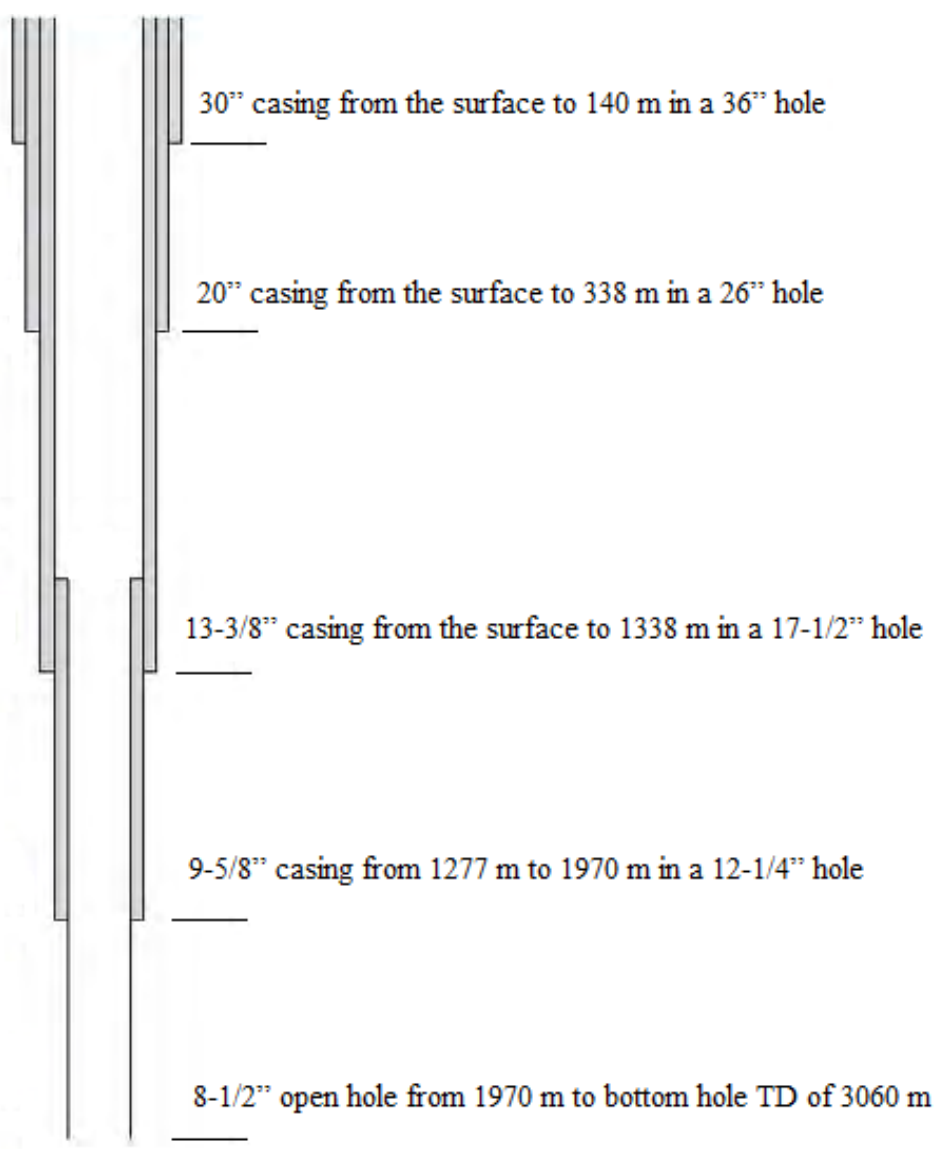

Figure 3.2 NWG 55-29 wellbore and casing profile Note: Figure 3.2 is not drawn to scale.

With the purpose of optimizing the system for the Newberry well, it is essential to use the NWG 55-29 well casing design for the wellbore model. This is necessary because the casing diameter and insulation design parameters determine the overall heat transfer coefficient, $U_{c}$. This directly affects the fluid temperature which ultimately affects every temperature dependent variable, most notably, the pressure.

\subsubsection{Wellbore model predictions}

Water at $30^{\circ} \mathrm{C}$ is pumped into the injection well with a wellhead injection pressure of $15 \mathrm{MPa}$. The wellbore model is used to predict the temperature and pressure that the geothermal fluid will enter the reservoir, or more specifically the fractured rock zones. The effects from thermal diffusivity will cause the wellbore fluid (injection fluid) to decrease the temperature of the wellbore over time. Data illustrating the effect of thermal diffusivity in the injection well are provided in Figure 3.3. 


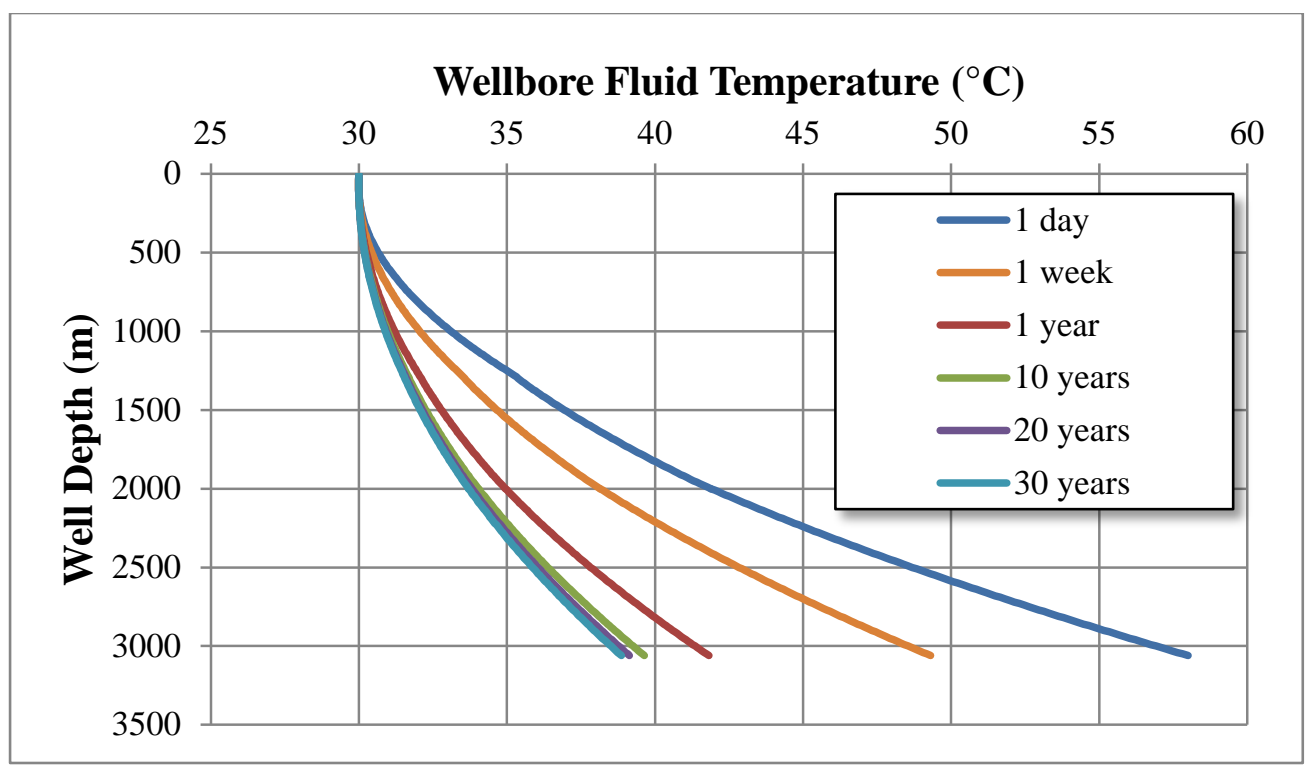

Figure 3.3 The wellbore fluid temperature with respect to well depth for a variety of injection timespans

Figure 3.3 illustrates how large of an impact the timespan of fluid injection has on the temperature of the fluid as it reaches the bottom-hole depth of $3060 \mathrm{~m}$. At short injection timespans, the cold injection fluid has not had adequate time to cool the wellbore. It should be noticed that after injecting for a long time period, the fluid temperature at the bottom-hole depth nears equilibrium. The relationship between bottom-hole temperature and time is critical to modeling the reservoir since it is used as the initial conditions. This relationship is provided in Figure 3.4.

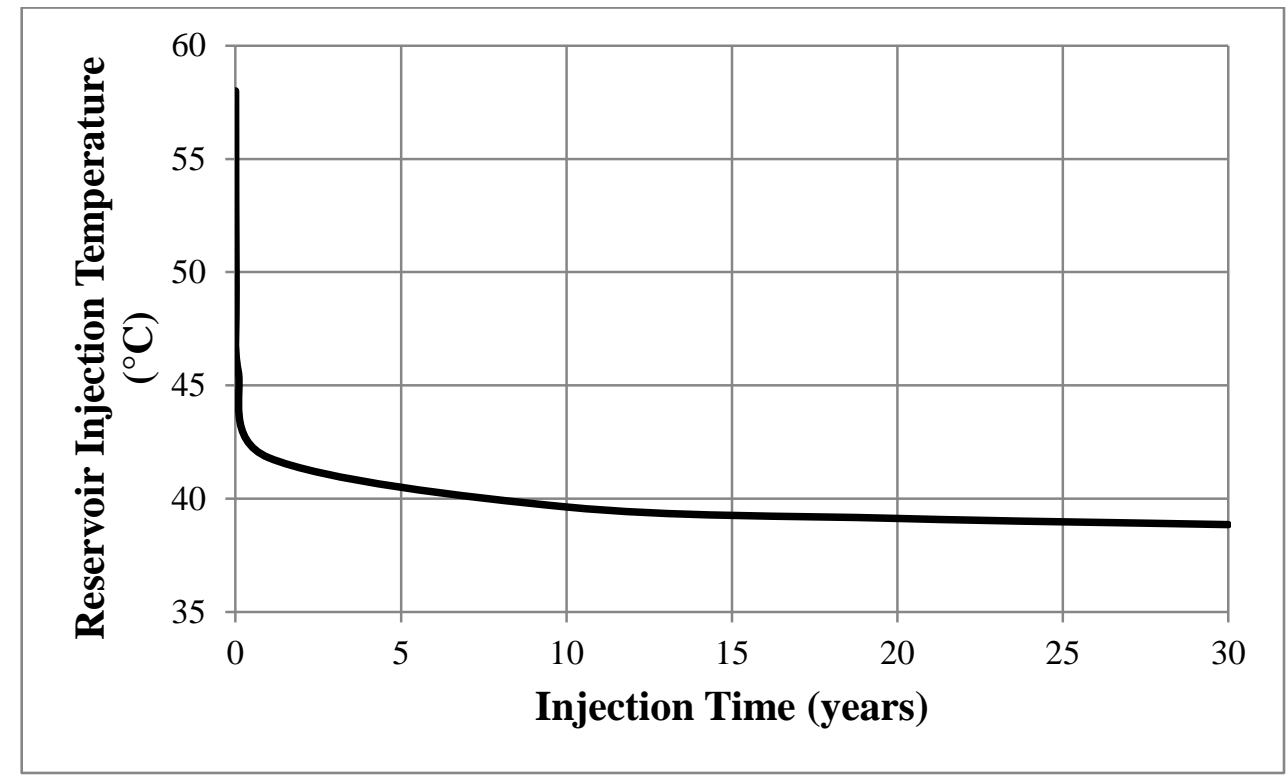

Figure 3.4 Bottom-hole injection temperature, or reservoir injection temperature, with respect to injection time 
Figure 3.4 reiterates the temperature-time relationship that is illustrated in Figure 3.3. It is also required to predict the pressure at the bottom-hole depth. The change in pressure within the wellbore is illustrated in Figure 3.5.

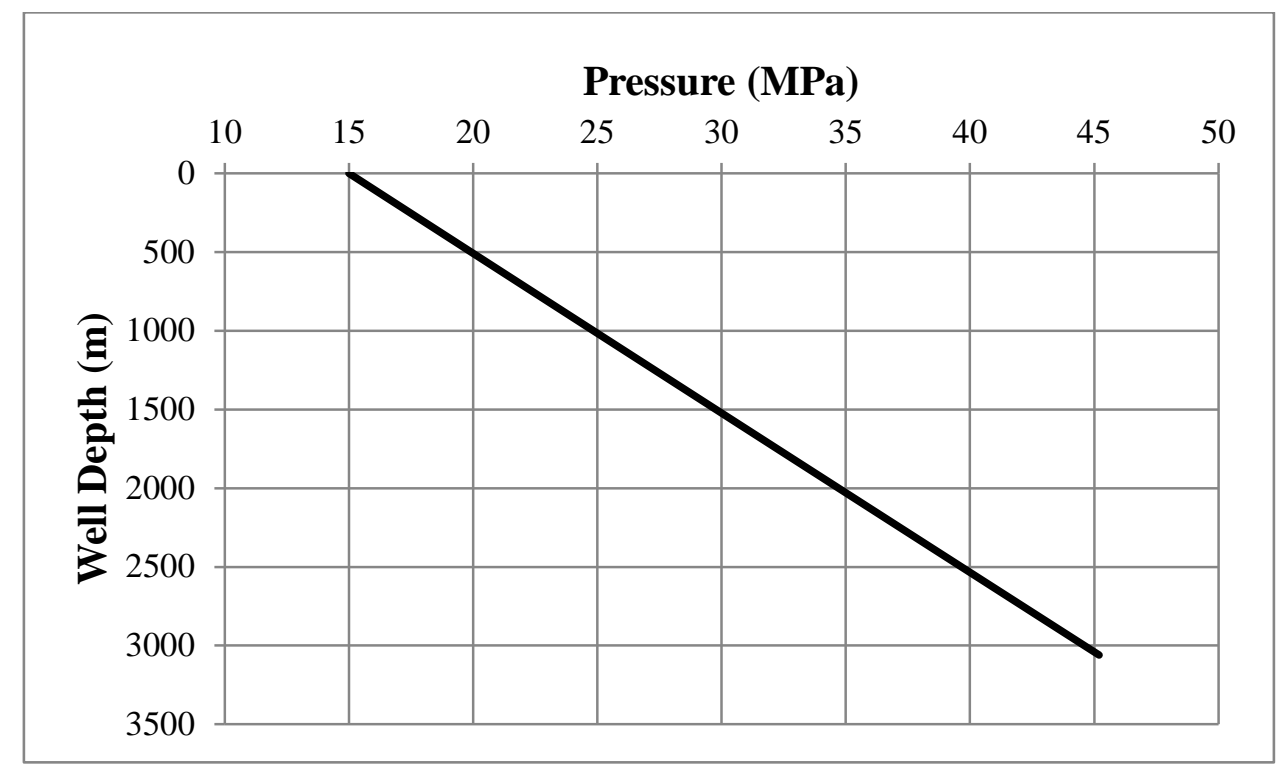

Figure 3.5 The change of pressure during injection predicted by the wellbore model

Injection timespan does not have a significant effect on the bottom-hole pressure. Therefore, the stimulation pressure is always around $45 \mathrm{MPa}$. The temperature and pressure data shown in Figures 3.4 and 3.5 are used for the injection conditions into the fractures for the reservoir modeling in TOUGH2. The entry pressure of $45 \mathrm{MPa}$ (wellhead pressure + hydrostatic head pressure) must be large enough to overcome the pressure losses in the fracture network and also the production well. Also, it is recommended that the injection pressure be high enough to avoid having the fluid drop below its flash pressure resulting in two-phase flow in the wellbore or in the reservoir.

For the production portion of the wellbore model predictions, the effects of thermal diffusivity are less drastic. There are typically only a few degrees change in temperature from the bottom-hole of the production well to the surface plant. The minuteness of the thermal diffusive effects in the production well is illustrated in Figure 3.6. The comparison assumes a bottom-hole production well temperature of $298.7^{\circ} \mathrm{C}$. 


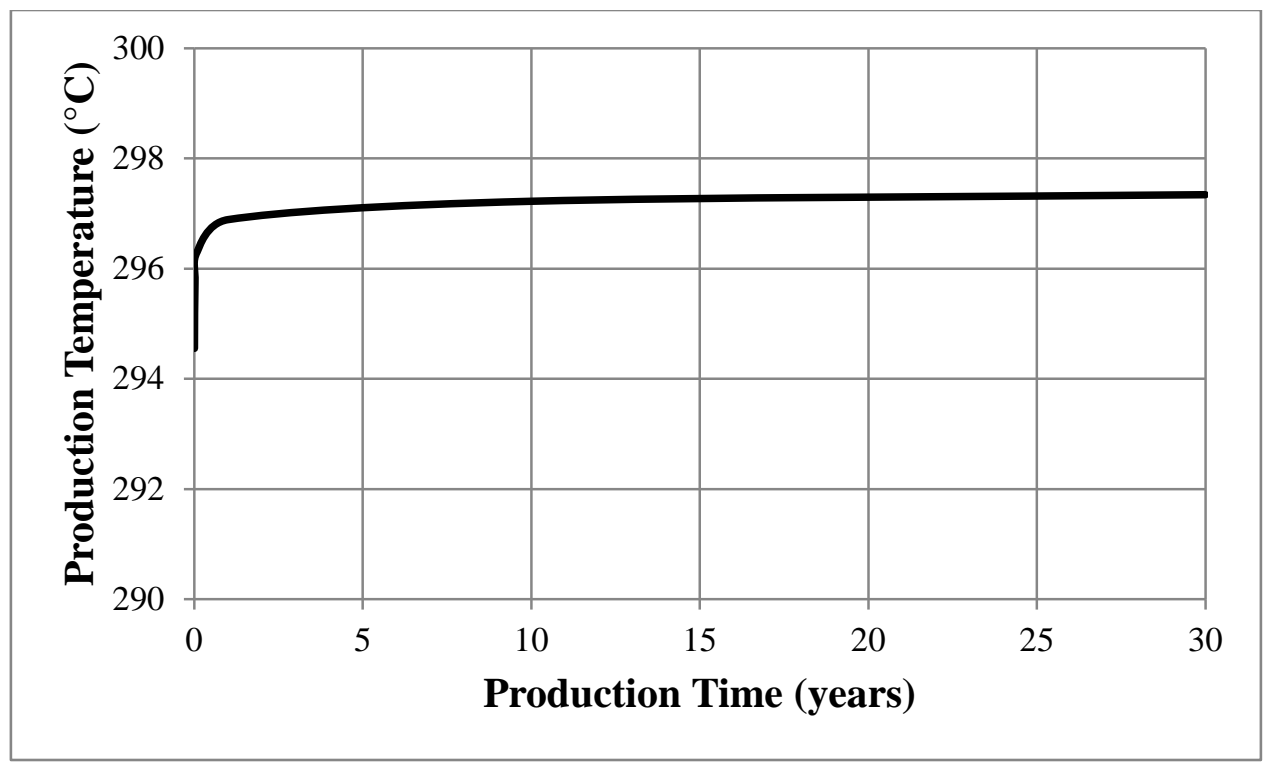

Figure 3.6 Production temperature with respect to production time assuming a bottom-hole production temperature of $298.7^{\circ} \mathrm{C}$

From Figure 3.6, it should be noticed that there is only a couple degree difference in the temperature change in the production well over a 30-year production timespan. In the actual geothermal system, the production well bottom-hole temperature will not be constant with respect to time; however, it was held constant in order to demonstrate the relative insignificance of thermal diffusivity in comparison to the temperature change from depletion of the thermal resource (will be illustrated in the next section).

It is also necessary to model the pressure losses in the production well. This is provided in Figure 3.7.

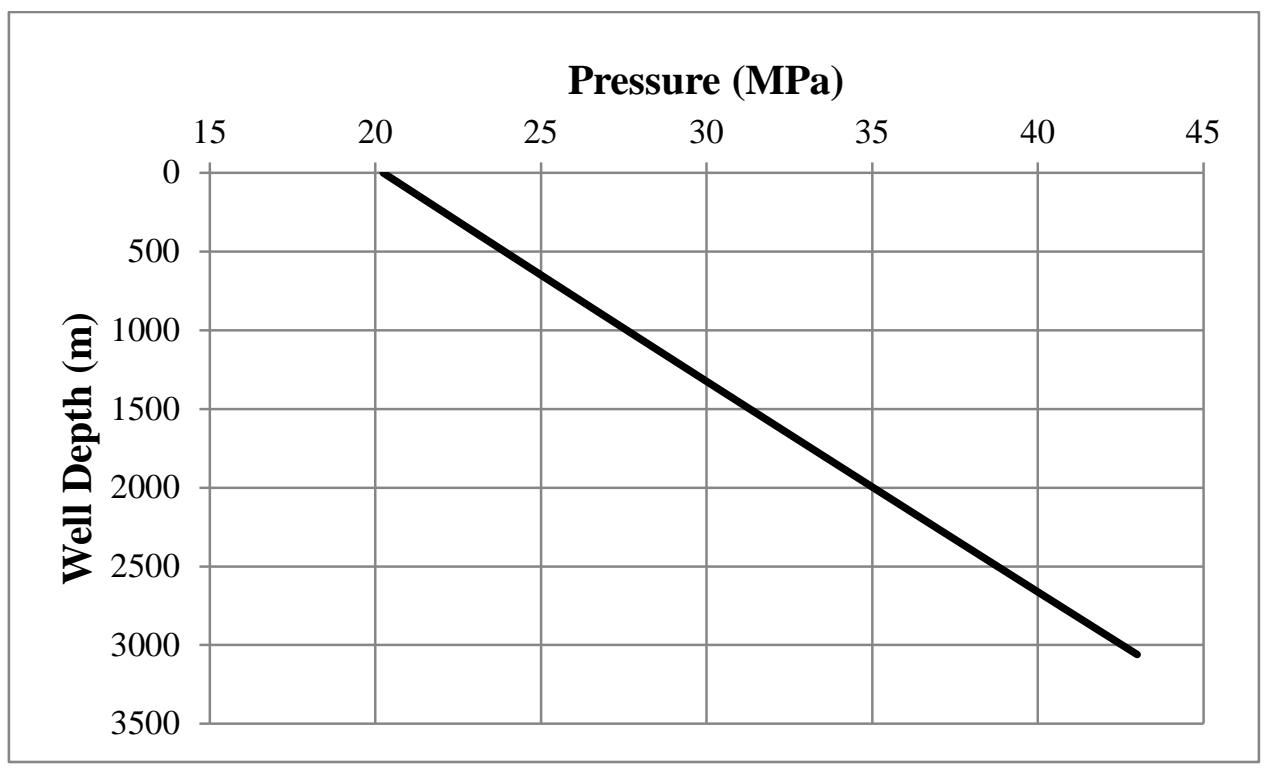

Figure 3.7 Pressure drop in the production well predicted by the wellbore model 
It can be determined from Figure 37 that the geothermal fluid pressure is around $20 \mathrm{MPa}$ upon reaching the surface and prior to being utilized at the surface power plant. The data provided in Figures 3.3-3.7 are used in the optimization and design of the reservoir and surface power plant.

\subsubsection{Reservoir design}

After ensuring that the system is modeled as close as possible to the NWG 55-29 well, then it is possible to investigate the optimization parameters. This study presents an enhanced geothermal reservoir located at the bottom-hole depth of $3060 \mathrm{~m}$. The reservoir has initial conditions of $300^{\circ} \mathrm{C}$ and $45 \mathrm{MPa}$. It is designed to produce water at the reservoir temperature, $300{ }^{\circ} \mathrm{C}$, and a constant fluid mass flow rate of 75 $\mathrm{kg} / \mathrm{s}$. Due to the depletion of the thermal energy in the reservoir, the production well will see a decrease in fluid temperature with respect to time. The reservoir was created using TOUGH2 and consists of one injection well and one production well connected by $500 \mathrm{~m}$ of a fractured rock zone. Reservoir stimulation is simulated for a 30-year operating timespan. The fractures consist of a 6-cm wide fractured zone with enhanced permeability and are perpendicular to the open hole. They extend $500 \mathrm{~m}$ in the direction of the production well and $1000 \mathrm{~m}$ into the rock in the third direction. It is necessary to choose realistic values for the fracture permeability and porosity. A fractured zone permeability of $100 \mathrm{mD}$ is used, and the fractured zone porosity is 0.1 . Both are reasonable values. The permeability is the same in the $x, y$, and $z$ direction. For the modeling, it is assumed that the rock porosity outside of the fractured zone is zero; therefore, there is only fluid flow within the fractured zone. Other than the porosity and permeability, the rock properties are consistent throughout the engineered reservoir. The model incorporates the rock density, heat capacity, and thermal conductivity that are present at Newberry. Although improbable in an actual EGS, the reservoir is simulated with the assumption of no geothermal fluid loss in the engineered reservoir. The rock properties that are used for the reservoir modeling and wellbore model are provided in Table 3.1.

Table 3.1 Rock properties

\begin{tabular}{|l|l|l|l|l|l|}
\hline & $\begin{array}{l}\text { Density } \\
\left(\mathrm{kg} / \mathrm{m}^{3}\right)\end{array}$ & $\begin{array}{l}\text { Heat capacity } \\
\left(\mathrm{J} / \mathrm{kg}^{\circ} \mathrm{C}\right)\end{array}$ & $\begin{array}{l}\text { Thermal cond. } \\
\left(\mathrm{W} / \mathrm{m}^{\circ} \mathrm{C}\right)\end{array}$ & $\begin{array}{l}\text { Permeability } \\
(\mathrm{mD})\end{array}$ & Porosity \\
\hline $\begin{array}{l}\text { Rock properties outside } \\
\text { of the fractured zones }\end{array}$ & 2400 & 879 & 6.9 & 0 & 0 \\
\hline $\begin{array}{l}\text { Rock properties within } \\
\text { the fractured zones }\end{array}$ & 2400 & 879 & 6.9 & 100 & 0.1 \\
\hline
\end{tabular}


Three different fracture networks were created and simulated using the numerical simulator TOUGH2.

The base case fracture network design consists of three fractures located at the bottom-hole depth of 3060 $\mathrm{m}$. The fractures are separated by $50 \mathrm{~m}$ along the open hole. Each fracture carries a fluid mass flow rate of $25 \mathrm{~kg} / \mathrm{s}$ yielding a total flow rate of $75 \mathrm{~kg} / \mathrm{s}$. This mass flow rate is used for two reasons: (1) AltaRock has reported that $25 \mathrm{~kg} / \mathrm{s}$ is about the maximum achievable flow rate in a fractured zone, and (2) it is stated in The Future of Geothermal Energy that the production flow rate must be at least $50 \mathrm{~kg} / \mathrm{s}$ per production well in order for an EGS to be economically viable [Tester, et al., 2006]. The second fracture network also consists of three fractures; however, in this design the fractures are separated by $100 \mathrm{~m}$ instead of $50 \mathrm{~m}$. The purpose of this comparison is to quantify the effect of fracture proximity to production fluid temperature. The third fracture network contains five fractures. The fractures are separated by $100 \mathrm{~m}$ in order to reduce the temperature effects from the adjacent fracture. Since this network consists of five fractures, each fracture will only carry $15 \mathrm{~kg} / \mathrm{s}$ as opposed to $25 \mathrm{~kg} / \mathrm{s}$ yielding the same total flow rate of $75 \mathrm{~kg} / \mathrm{s}$. The goal of this comparison is to assess the relationship between flow rate and reservoir temperature depletion (production temperature). A visualization from PetraSim of the base case fracture network design in operation is provided in Figure 3.8.

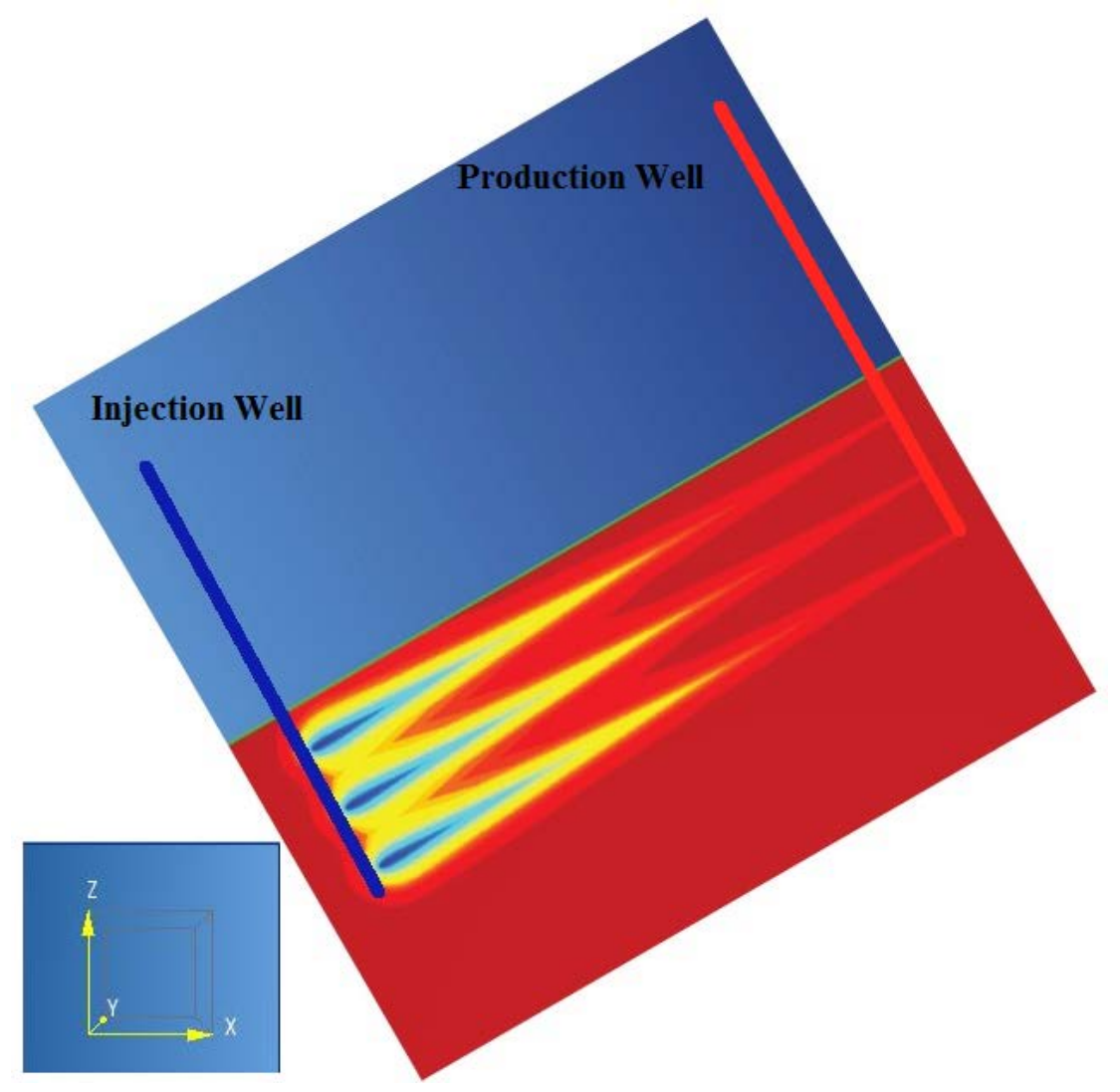

Figure 3.8 Visualization from PetraSim of the base case design 


\subsubsection{Reservoir simulation results}

The reservoir simulations provide temperature data of the reservoir with respect to time. These data can be analyzed to determine which fracture network design will provide the greatest power production at the surface plant. As mentioned in the previous section, the base case fracture network design consists of three fractured zones separated by 50 m of rock. Figures 3.9-3.12 provide a visual depiction of the temperature depletion in the reservoir as production time increases for the base case design.

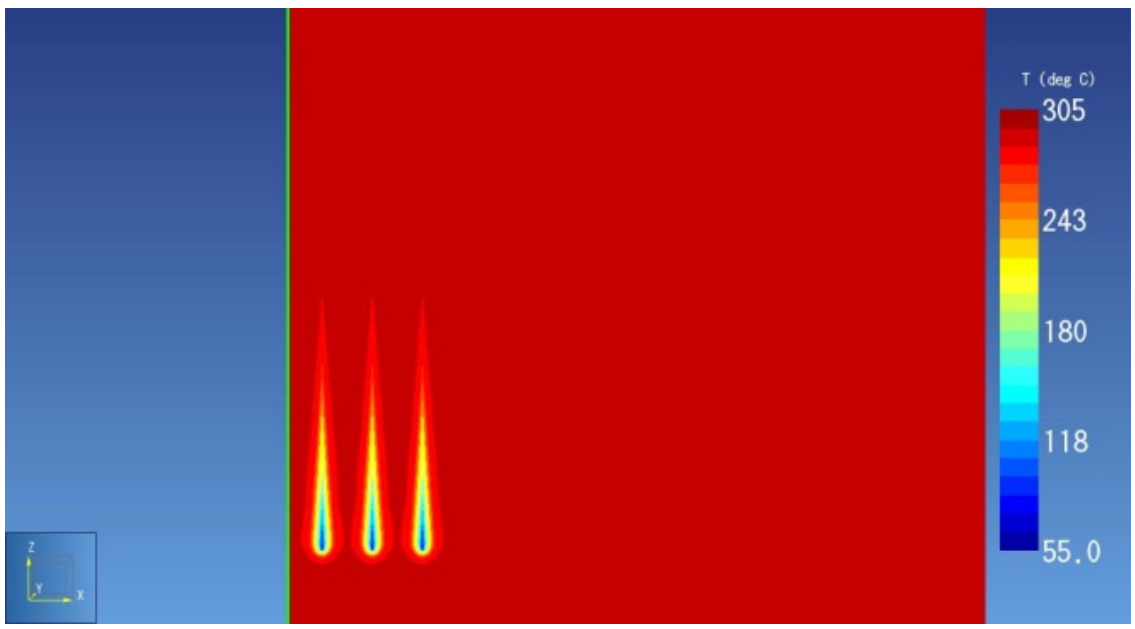

Figure 3.9 Change in reservoir temperature after 1 year of production for 50-m spacing

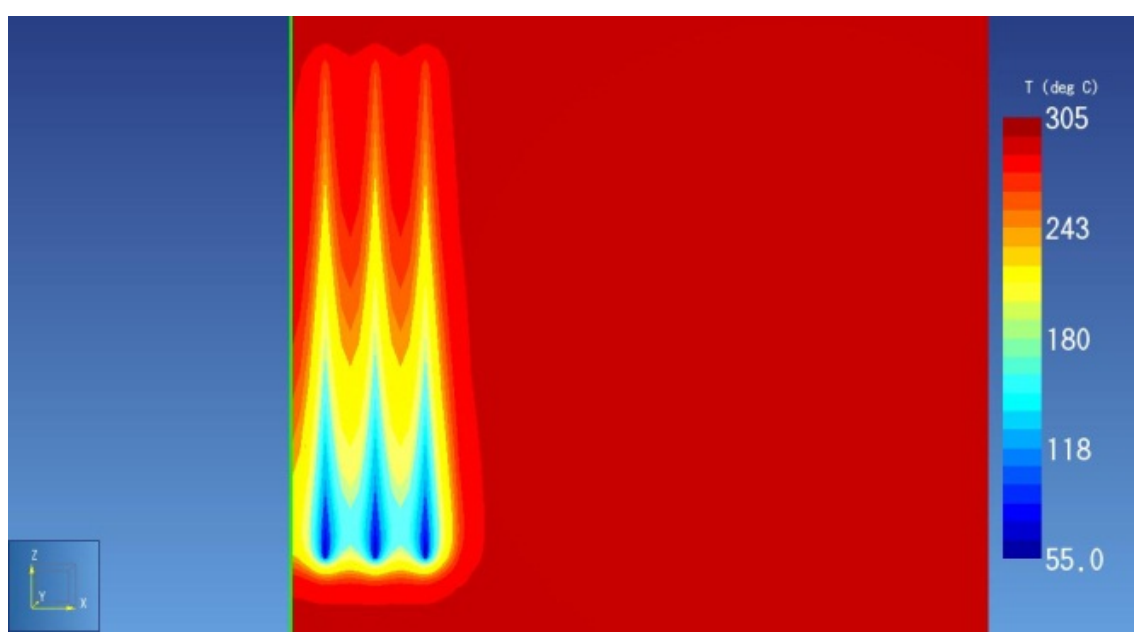

Figure 3.10 Change in reservoir temperature after 10 years of production for 50 -m spacing 


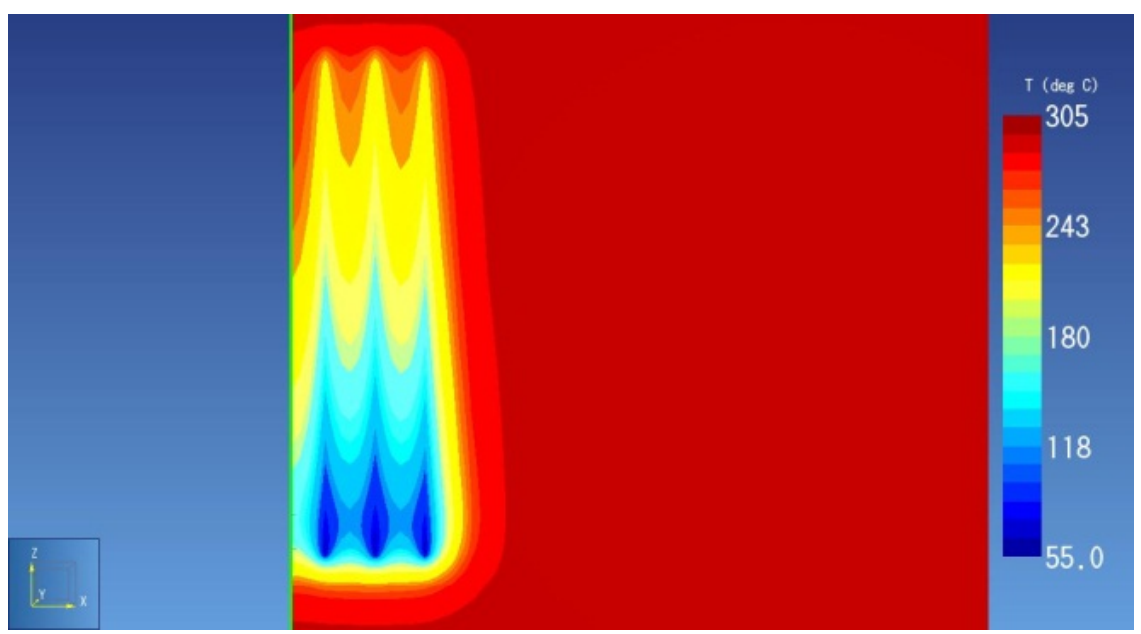

Figure 3.11 Change in reservoir temperature after 20 years of production for 50-m spacing

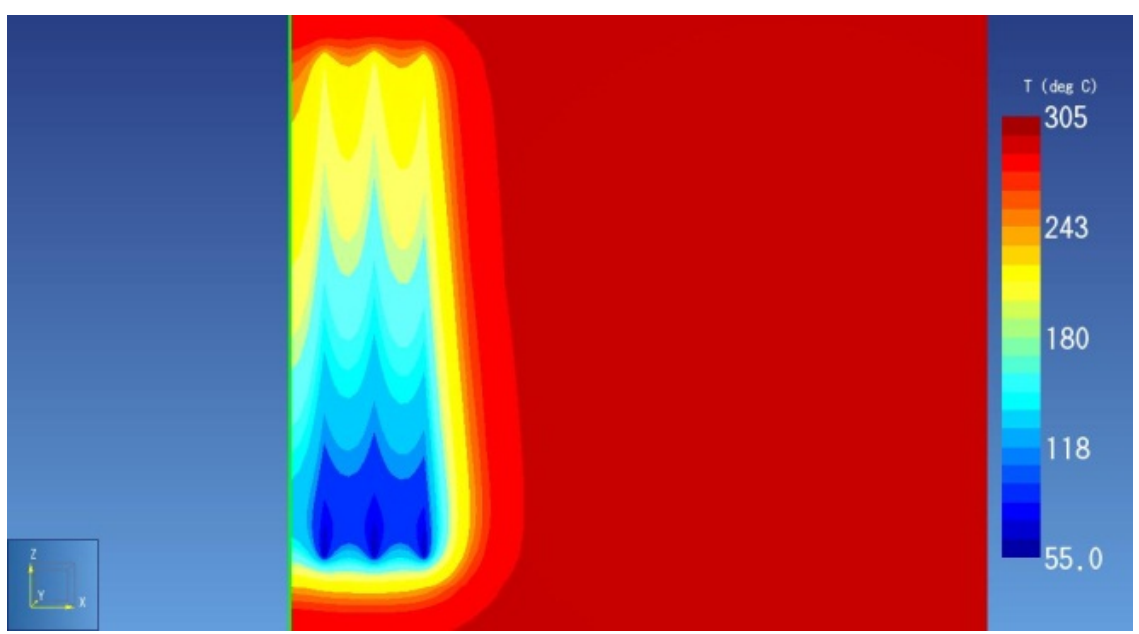

Figure 3.12 Change in reservoir temperature after 30 years of production for 50-m spacing

Upon examination of Figures 3.9-3.12, it is noticed that by year 30 the reservoir has been much depleted. The reservoir temperature near the production well has dropped from $300^{\circ} \mathrm{C}$ to around $200^{\circ} \mathrm{C}$. Also, it should be noticed that the fracture temperatures are significantly impacted by cooling from adjacent fractures. The effect of adjacent wells is more easily noticed when the production temperature of each fracture is examined as a function of time. This relationship is shown in Figure 3.13. 


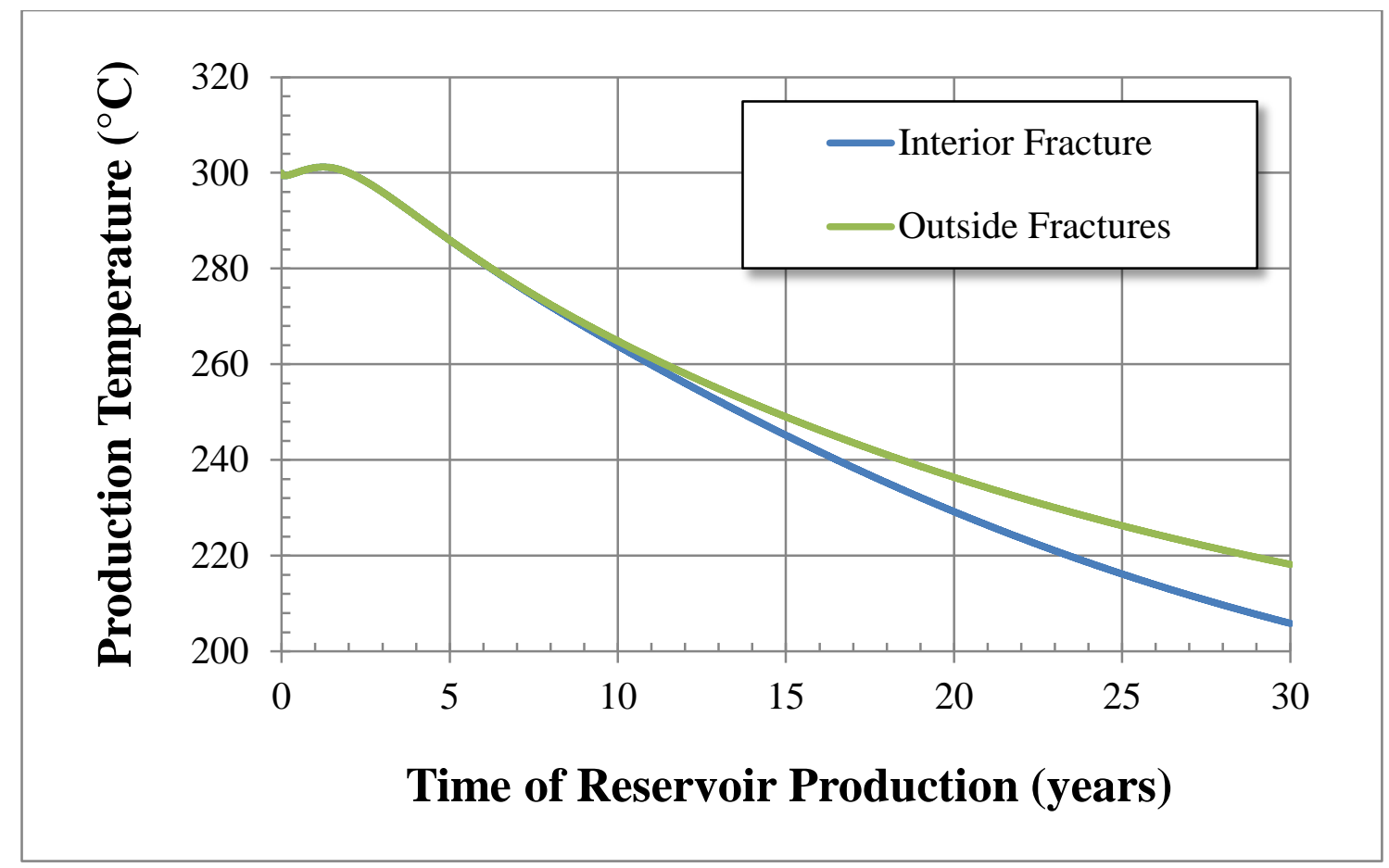

Figure 3.13 Comparison of the temperature change with time for the interior fracture and the two outside fractures

It can be determined from Figure 3.13 that the 50-m fracture spacing is not enough distance between fractures if the desire is to operate for over 20 years at this mass flow rate. The interior fracture experiences more cooling, and thus a lower production temperature, due to the effects from the adjacent fractures. It should be noticed that the temperature-time relationship for the fractures is identical for the first 10 years of reservoir stimulation. This is because the thermal cooling has yet to penetrate far enough into the reservoir to affect the adjacent fractures. Ideally, the fractures would be separated by a large enough distance to avoid any cooling effects from adjacent fracture zones. For this reason, further fracture separation will be examined.

The second fracture network to be investigated is the three fracture network with 100-m spacing. Figures 3.14-3.17 provide a visual depiction of the temperature depletion in the reservoir as the production time increases. 


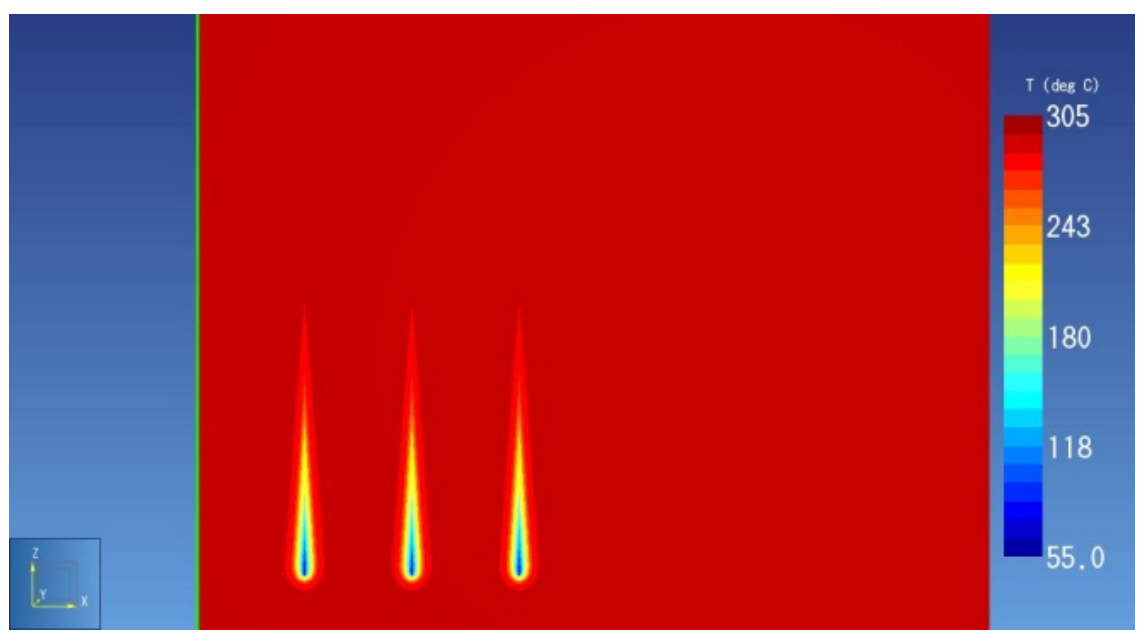

Figure 3.14 Change in reservoir temperature after 1 year of production for 100-m spacing

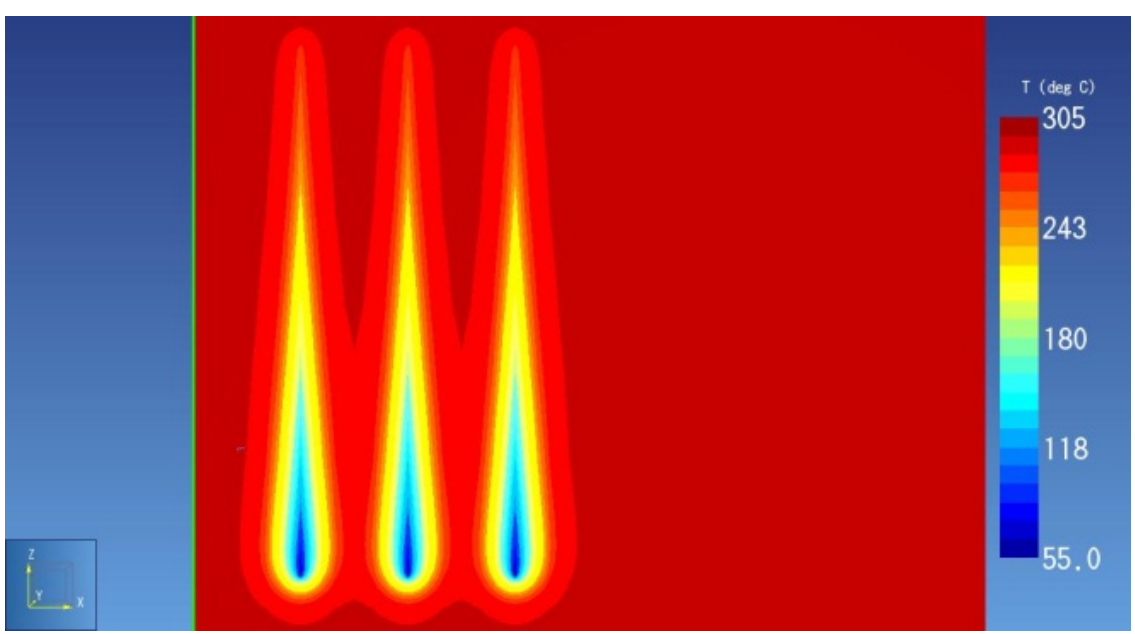

Figure 3.15 Change in reservoir temperature after 10 years of production for 100-m spacing

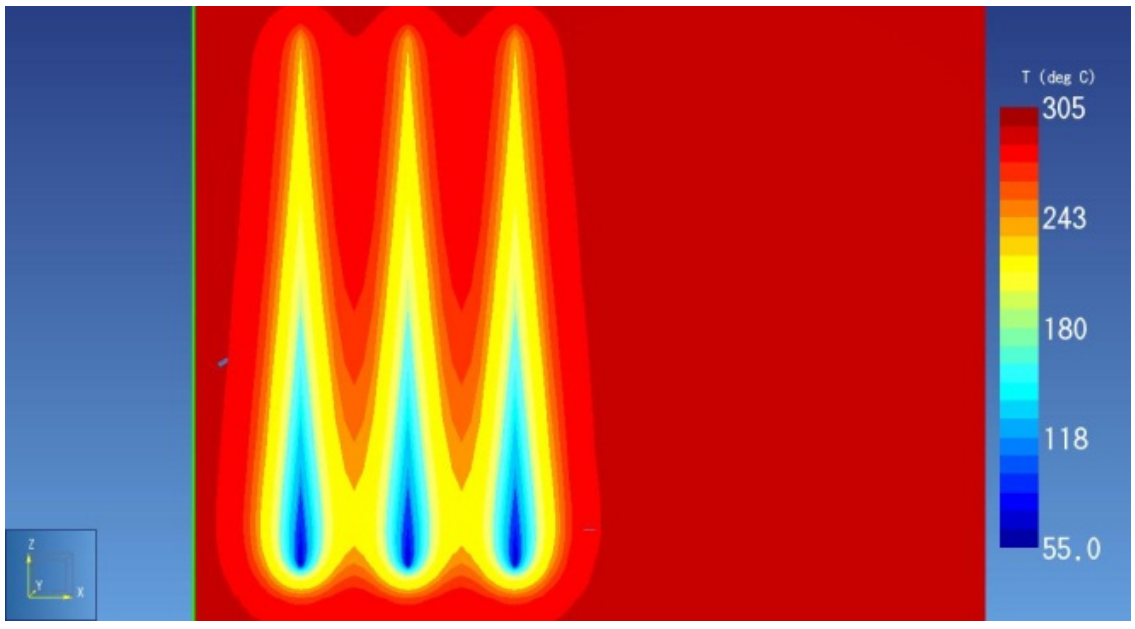

Figure 3.16 Change in reservoir temperature after 20 years of production for 100-m spacing 


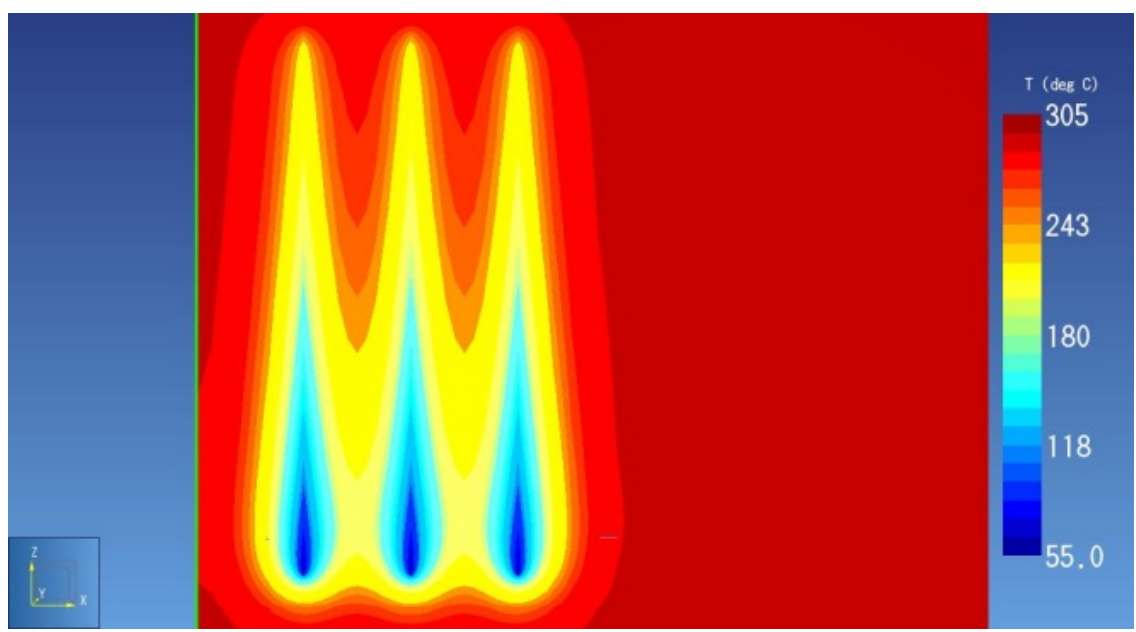

Figure 3.17 Change in reservoir temperature after 30 years of production for 100-m spacing

It can be determined from examination of Figures 3.14-3.17 in comparison to Figures 3.9-3.12 that 100-m well spacing does not cause as much reservoir temperature depletion for these injection conditions. At this larger fracture spacing, there is an insignificant amount of temperature difference between the interior fracture and the two exterior fractures. However, it is noticed that, although the reservoir does not appear to be as depleted as the base case design, there is still significant cooling in the reservoir. Adding two fractured zones ( 5 fractures as opposed to 3 fractures) and therefore lowering the mass flow rate per fracture (15 kg/s as opposed to $25 \mathrm{~kg} / \mathrm{s}$ ) will yield a more favorable production temperature profile with respect to time. This is investigated in the final fracture network design.

The last fracture system design is a five-fracture system with $100 \mathrm{~m}$ of separation between the fractures. The reservoir temperature as production time increases is depicted in Figures 3.18-3.21.

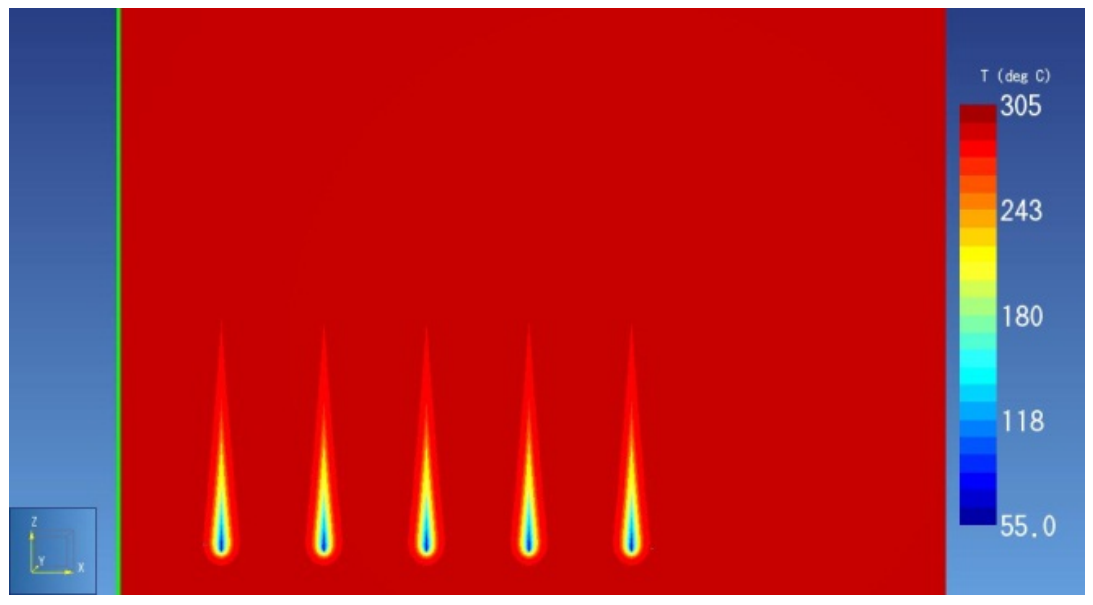

Figure 3.18 Change in reservoir temperature after 1 year of production for the five-fracture system with 100-m spacing 


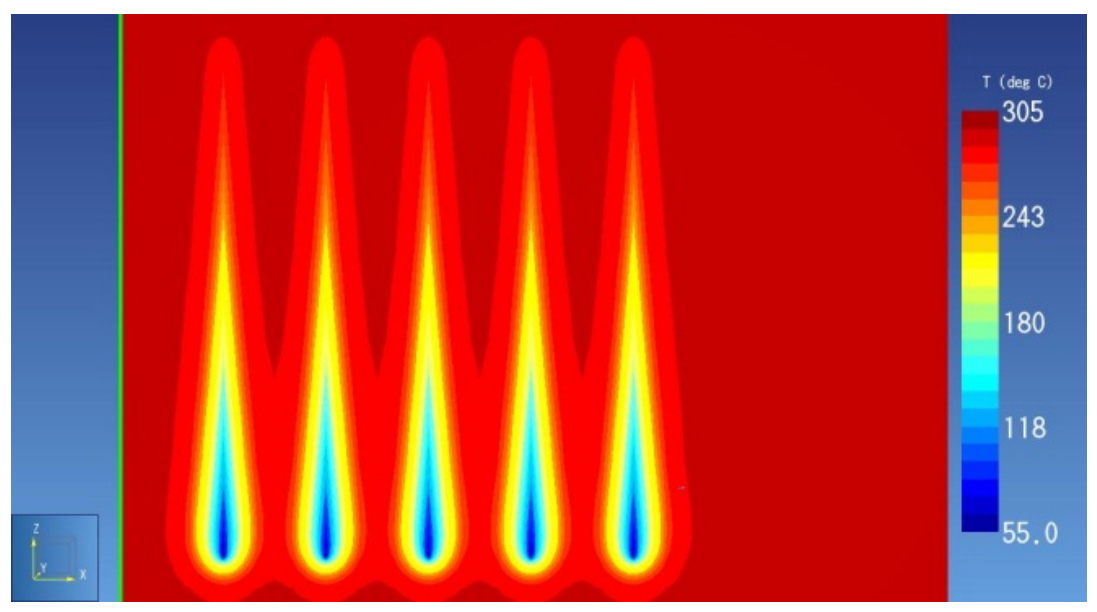

Figure 3.19 Change in reservoir temperature after 10 years of production for the five-fracture system with 100-m spacing

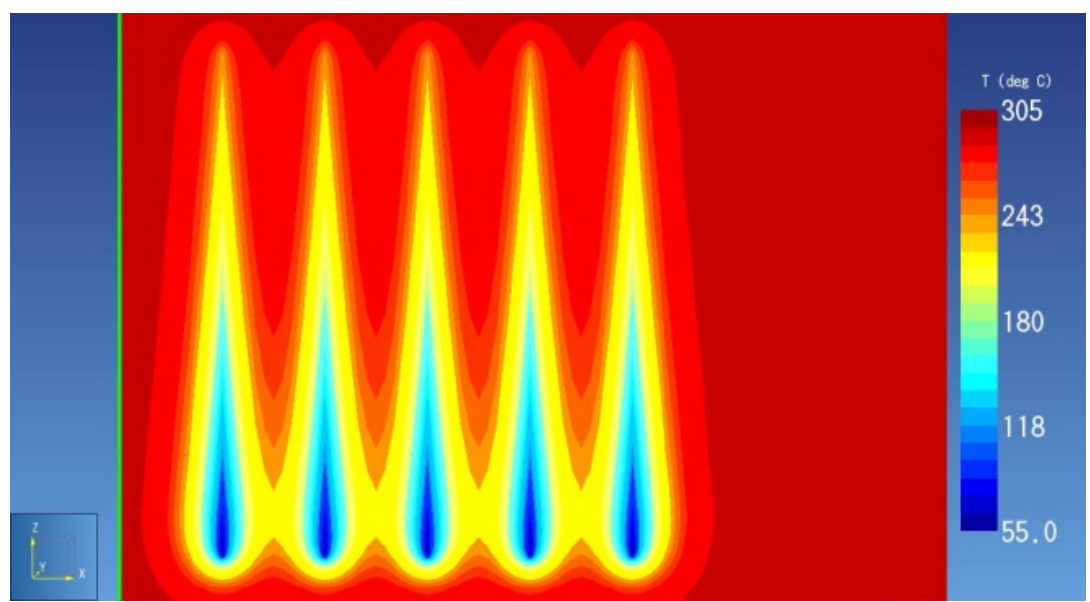

Figure 3.20 Change in reservoir temperature after 20 years of production for the five-fracture system with 100-m spacing

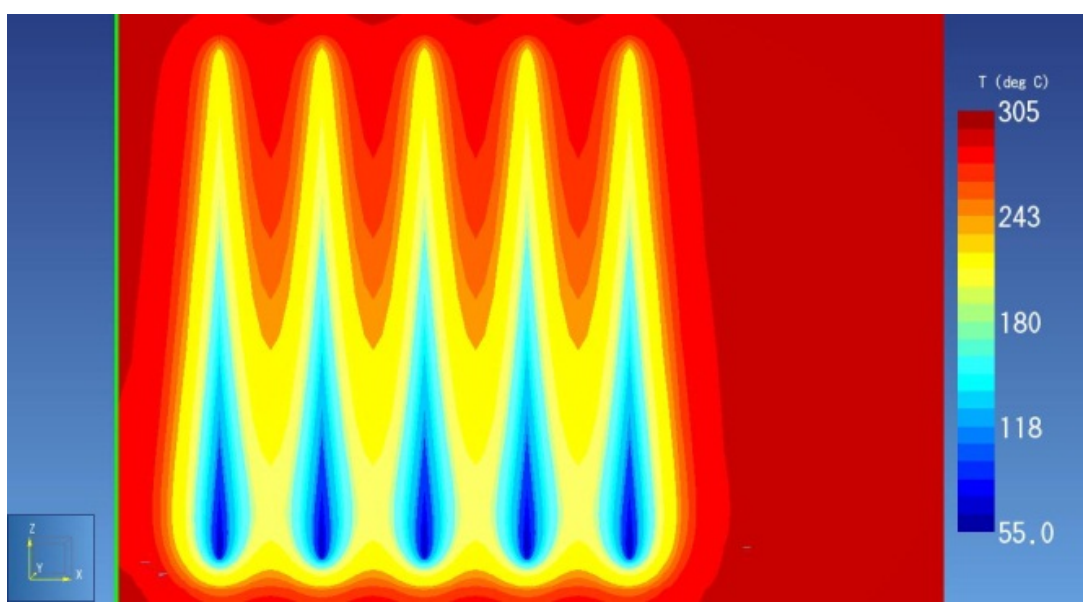

Figure 3.21 Change in reservoir temperature after 30 years of production for the five-fracture system with 100-m spacing 
From just comparing the two 100-m fracture spacing designs visually, it is not easily noticed whether the decreasing of the flow rate has a significant difference on the reservoir temperature depletion and the production temperature with respect to time. In order to determine the significance, it is necessary to compare the production temperature as a function of time. This comparison of all three fracture network designs is provided in Figure 3.22.

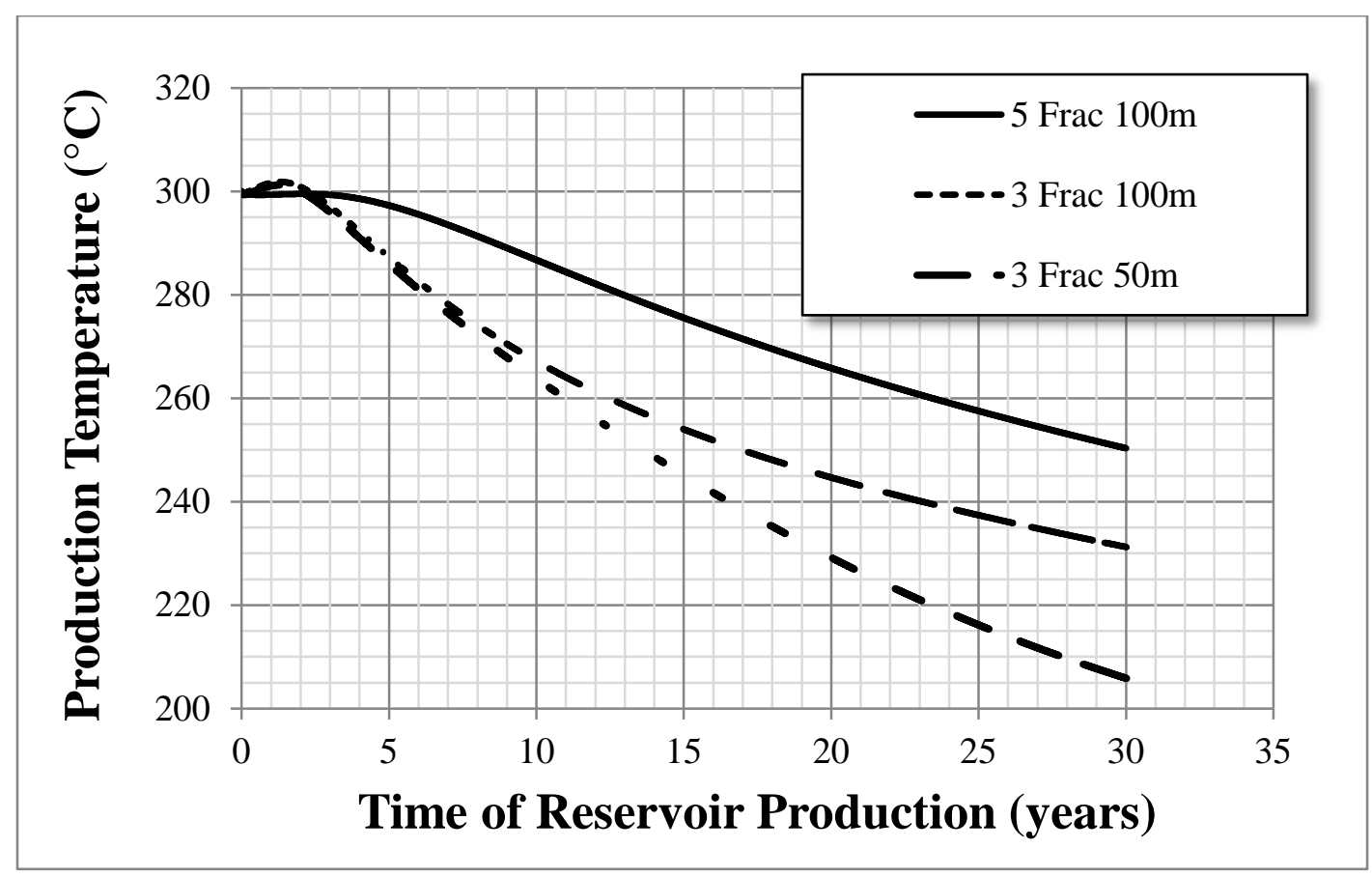

Figure 3.22 Comparison of the decrease in production temperature with respect to reservoir stimulation time for all three fracture networks that were investigated

Figure 3.22 demonstrates the significant difference among the three fracture networks that were investigated in this study.

Since the study of fractured/stimulated geothermal reservoirs is in its infancy, there are not comprehensive data regarding the expenses associated with creating a fracture network. Ideally, the goal would be to recommend a fracture network design based on quantifiable costs derived from reliable costing estimate equations. These costing equations would allow one to determine whether the cost of the additional fractures is overcome by the increased electricity generated at the surface plant over the 30year operating time. However, due to the lack of data, this study will recommend a fracture network based on thorough qualitative analysis of the engineered reservoir. It is hypothesized that the fivefracture system will yield a greater net profit over the EGS lifetime. The production results from the fivefracture system will be used for the optimization of the surface plant. 


\subsection{Surface plant design}

\subsubsection{Topological surface plant optimization}

In order to optimize the entire geothermal system, a topological and parametric optimization of the surface plant had to be completed in conjunction with the subsurface design. When designing the surface component of an EGS, the first variable to consider is the temperature of the production fluid. Since the bottom-hole temperature at the Newberry well exceeds $300^{\circ} \mathrm{C}$, it is recommended that a power plant for electricity generation is designed at the surface as opposed to direct-use of the geothermal fluid. A flashsteam power plant is the best way to generate electrical power from a high-temperature liquid when water recovery is not a primary concern. For this EGS optimization, it is assumed that water supply is not a significant issue; therefore, a flash-steam power plant is designed as opposed to using a binary cycle power plant. The design and optimization of the surface plant were completed using the chemical process simulation software CHEMCAD.

This system needed to be optimized for a single-flash design and also for a double-flash design in order to determine which design yields the greater power output. This is the only design parameter investigated for the topological optimization of the surface plant. For the optimization, the flash conditions are varied to determine the maximum power rating of the power plant. The optimal separation temperature occurs near the halfway temperature between the production fluid temperature and the temperature of the steam condenser. This optimization arises because the power output of the turbine is dependent on both the mass flow rate of the steam and the enthalpy difference across the turbine. Figure 2.5 in Section 2.3.3 can be referred to for the schematic of a flash-steam power plant. A low separation temperature will result in a greater mass flow rate of the steam; however, the steam will have lost more enthalpy. On the contrary, a higher separation temperature will offer less steam to the turbine but will retain a higher enthalpy. For this reason, the optimal separation temperature falls somewhere near the middle.

For the case of just comparing the two different types of flash power plants, it is assumed that the production well temperature is $298^{\circ} \mathrm{C}$ for the plant lifetime and producing at a mass flow rate of $75 \mathrm{~kg} / \mathrm{s}$. Production temperature will actually decrease with time, but this greatly complicates the optimization and does not need to be accounted for to accurately determine which power plant design is the better option of the two. Both power plant designs (single-flash and double-flash) are optimized for the constant production temperature in order to determine which flash plant provides the greater power plant rating. The results of the single-flash power plant optimization are provided in Figure 3.23. 


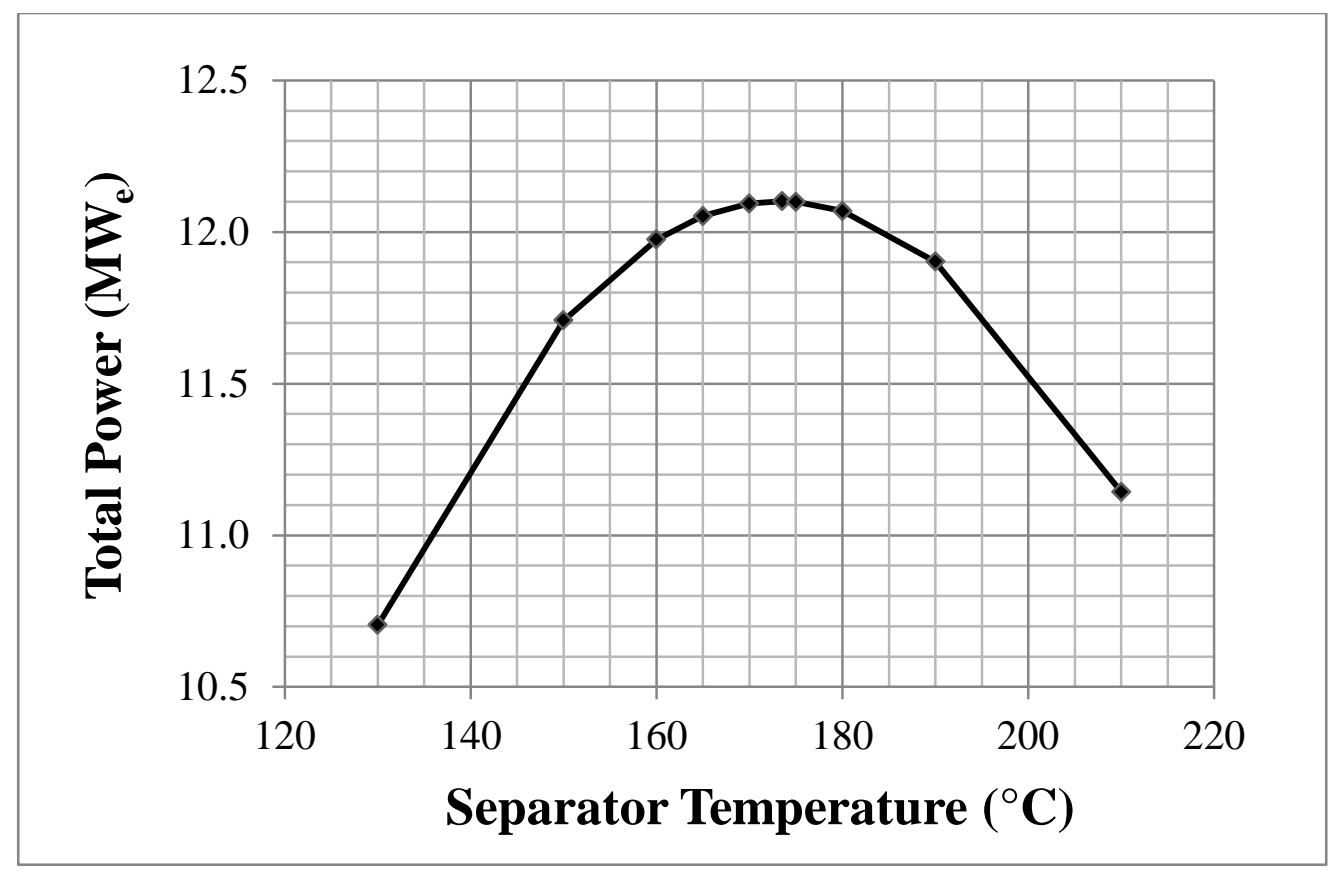

Figure 3.23 Single-flash power plant optimization for a constant production fluid temperature of $298{ }^{\circ} \mathrm{C}$

It can be determined from the results provided in Figure 3.23 that the optimal separator temperature is around $175^{\circ} \mathrm{C}$. This separator temperature will yield a power plant rating of around $12.1 \mathrm{MW}_{\mathrm{e}}$.

Due to the additional separation vessel in the double-flash system, there is another variable in optimization. A temperature is chosen for the first separation while the temperature of the second vessel is varied. This is repeated for multiple temperatures of the first separation. The results of the doubleflash power plant optimization are provided in Figure 3.24. 


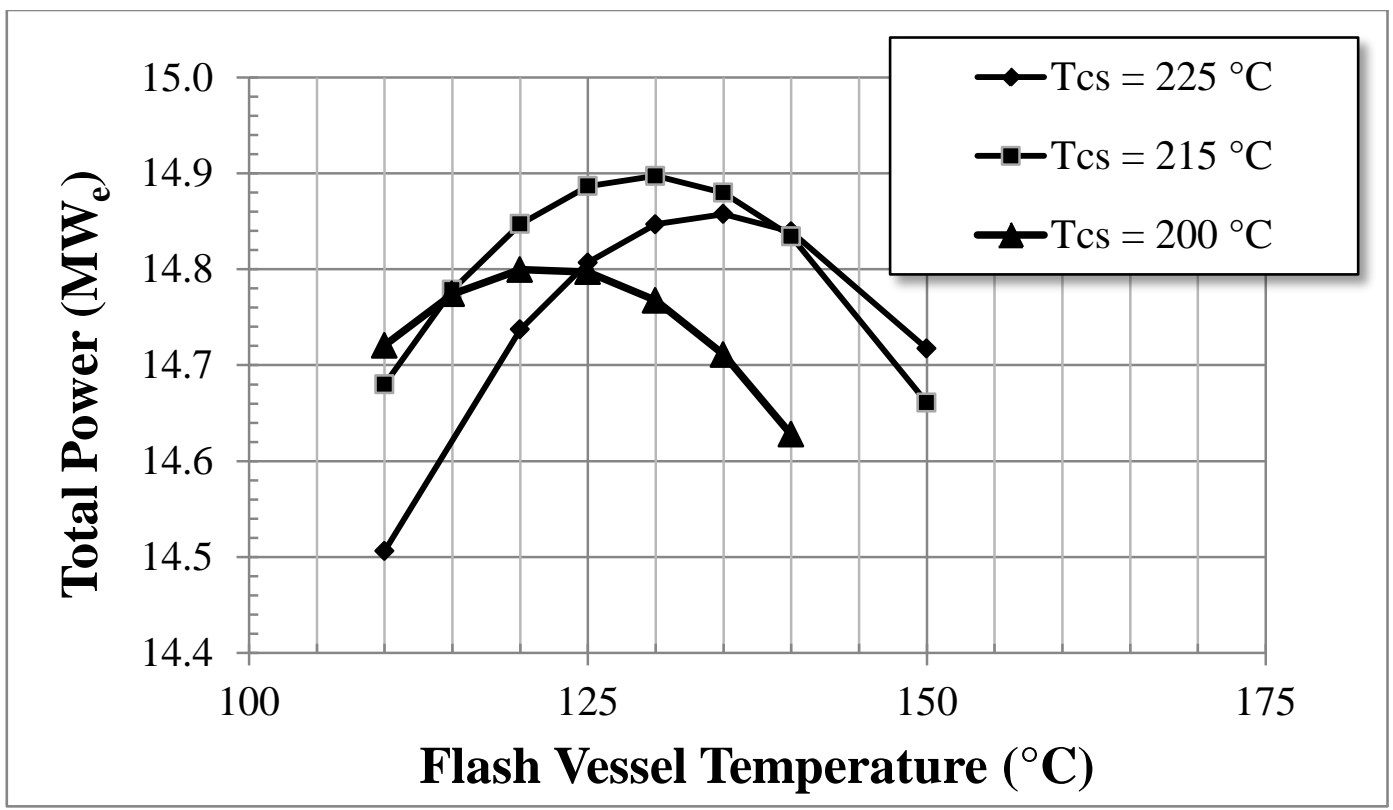

Figure 3.24 Double-flash power plant optimization for a constant production fluid temperature of $298^{\circ} \mathrm{C}$

From Figures 3.23 and 3.24, it is apparent that the double-flash provides a higher power output as expected. $T_{c s}$ is the temperature of the cyclone separator (first separation) with the flash vessel temperature (second separation) on the x-axis. Ideal conditions for this design are an initial separation of $215^{\circ} \mathrm{C}$ and a second separation temperature of around $130^{\circ} \mathrm{C}$, which yields a power output of $14.9 \mathrm{MW}_{\mathrm{e}}$. This is a 23.1\% improvement upon the single-flash power output of $12.1 \mathrm{MW}_{\mathrm{e}}$.

As mentioned, this is not the full surface plant optimization. These two comparisons were only completed to see if the double-flash power plant offers a significant enough increase in power output to warrant the extra flash vessel and turbine. A 23\% increase in power output provides a substantially greater amount of revenue compared to the cost associated with installing and operating an additional flash vessel. Therefore, the installation of a double-flash steam power plant is recommended for the production of electricity at Newberry.

\subsubsection{Parametric optimization of the double-flash steam power plant}

The goal of the parametric optimization is to determine the optimal operating conditions of the doubleflash steam power plant. The parametric optimization can be complicated since the temperature of the fluid from the production well is not constant over the operating lifetime of the plant. In any EGS where production is occurring in the same fracture network, temperature loss in the reservoir will be inevitable. Since thermal energy is constantly being extracted from the reservoir and not naturally being replenished 
at an equivalent rate, the surface plant will continually produce less power than at the initial injection. Because of the decrease in power generation with respect to time, the surface plant cannot be simply optimized for the initial temperature. Increased production flow rate will generate a greater amount of electrical power at the surface plant but will expedite depletion of the thermal resource.

Since the five-fracture system is recommended, its production temperature with respect to production time relationship will be used for optimization of the surface plant. This relationship is provided in Figure 3.25.

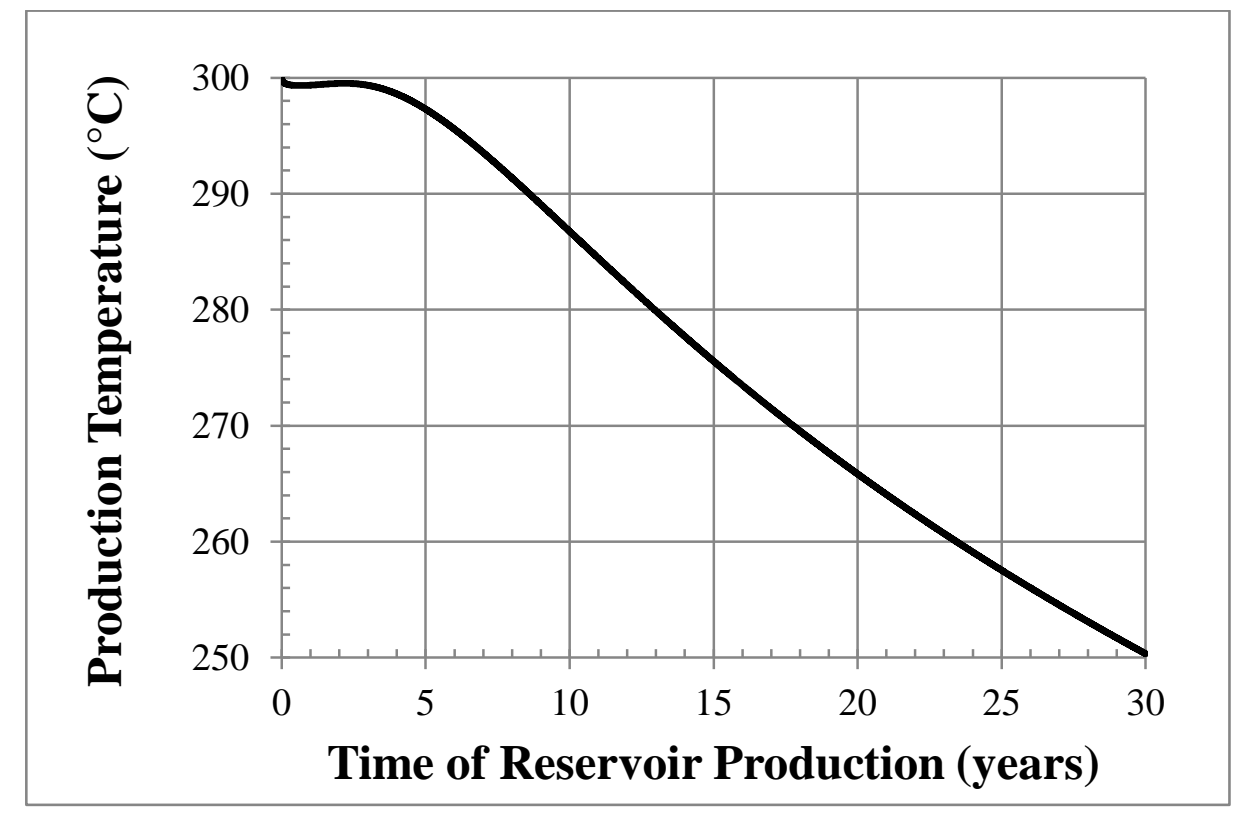

Figure 3.25 The production temperature as a function of time that will be used for the optimization of the surface plant

Ideally, one would want to use the relationship in Figure 3.25 as the inlet conditions in the surface plant simulations. However, it is not possible to input a time-dependent function as the inlet conditions in the chemical process simulator CHEMCAD. Since instantaneous inlet conditions cannot be used, it is necessary to choose a timespan for the calculation of the corresponding surface plant power rating. The smaller the timespan, the more accurate the optimization will be; however, a larger time span could likely still yield the optimal operating conditions. For this study, the reservoir production results will be divided into five 6-year time intervals. This is an adequately small time interval to yield the same optimization results as a surface system designed to use instantaneous inlet conditions.

Another variable that must be considered is the time value of money. Due to the opportunity to invest profits, money earned earlier in the production lifetime is worth more than the same amount of money 
earned at a later time. For this reason, money earned at a later time must be discounted back to a present value. The relationship that will be used is:

$$
P V_{j}=\frac{F V_{j}}{(1+i)^{n}}
$$

$P V_{n}$ is the present value in year $n, F V_{n}$ is the future value, $i$ is the annual interest rate, and thus $n$ is the year the $F V_{n}$ is earned. The $F V_{n}$ is determined from the energy produced over that time period. The power generated is divided into five 6-year time spans. For each timespan, the power output must be calculated for a variety of cyclone separator and flash vessel separator conditions. Then, this mean power output must be discounted back to the present value, $P V_{n}$. The power output is converted into a dollar amount using an electricity cost of $\$ 16.8 / G J$. An annual interest rate of 5\% is used for the time value of money calculations.

For example, the mean power output for a specific pair of separator conditions during years one through six is dependent on the mean production temperature during years one through six (refer to Figure 3.25). So this method assumes the power output for those six years is the same each year. Although the power generation is assumed the same in years one through six, the $P V_{n}$ of the money earned from this power generation actually decreases each year as because of the relationship in Equation 3.1.

The operating conditions that yield the greatest sum of the present values over the 30-year operation lifetime is recommended for the surface plant operation. This relationship of this summation is provided here:

$$
N P V=\sum_{j=1}^{30} P V_{j}
$$

The $N P V$ determined from Equation 3.2 is not the $N P V$ of the entire geothermal system. These values are inflated because they are only the profits from the electric generation discounted to the $P V_{n}$. This methodology is accurate in determining the optimal conditions because the only difference in expenses is going to be the very slight size difference in the separation vessels. These flash vessel costing differences are insignificant in comparison to the electricity generation of the surface plant. The $N P V$ for different pairs of separator conditions is provided in Figure 3.26. 


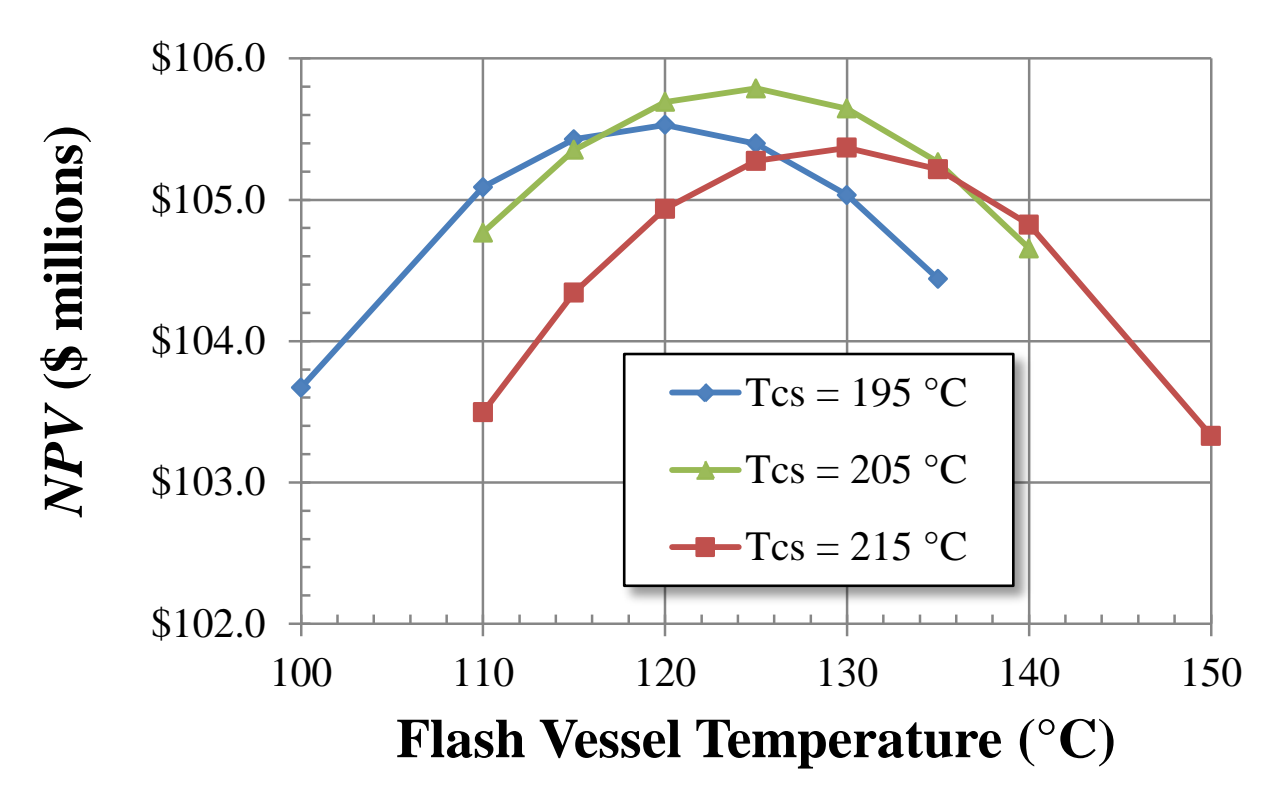

Figure 3.26 The $N P V$ of electricity generated from the steam turbines at varying separator temperatures.

A variety of cyclone separator conditions were investigated. Only the three that yield the greatest $N P V$ are provided in Figure 3.26. The optimal conditions for the double-flash steam power plant are operating the cyclone separator at a temperature of $205^{\circ} \mathrm{C}$ and operating the flash vessel at a temperature of $125^{\circ} \mathrm{C}$.

The subsurface reservoir optimization coupled with a parametric and topological optimization of the surface plant provides the conditions that allow for the greatest power generation for the Newberry well location. 


\section{CONCLUSIONS AND RECOMMENDATIONS}

\subsection{Conclusions}

The purpose of this study was to successfully integrate the reservoir, wellbore, and power plant components of an Enhanced Geothermal System and determine the optimal operating conditions for the production of electricity at the Newberry, Oregon well site. This well is currently the site of the Newberry EGS Demonstration Project performed by AltaRock and funded in part by the Geothermal Technologies Program at the DOE. The optimization consisted of subsurface and surface systems design. The wellbore model allowed for the present conditions at Newberry to be replicated in this optimization. The numerical reservoir simulation program TOUGH2 was used to design and simulate the stimulation of the engineered reservoir and different fracture networks. The chemical process simulator CHEMCAD was used to model the surface plant and determine which reservoir design and surface plant operating conditions would yield the greatest amount of electricity production over a 30-year plant operation lifetime.

It was determined that the fractured zones in the reservoir would need to be separated by more than $50 \mathrm{~m}$ for the mass flow rate of $75 \mathrm{~kg} / \mathrm{s}$. A separation of $50 \mathrm{~m}$ was only sufficient separation for operating times of around 15 years. The second fracture network has separation of $100 \mathrm{~m}$ and this yielded much more positive results. The final fracture network consisted of five fractures separated by $100 \mathrm{~m}$ resulting in a smaller mass flow rate per fracture. Due to the additional fractures, the same total mass flow rate could be achieved while lessening the reservoir resource depletion. In essence, this design distributed the heat mining over a larger region which allowed for the extraction of more thermal energy from the same total mass flow rate. This was the recommended reservoir design.

For the surface plant component, it was decided that the generation of electricity from a flash-steam power plant was the best option since the resource temperature is in excess of $300^{\circ} \mathrm{C}$. A double-flash design yielded 23\% more power than the single-flash design. A parametric optimization of the doubleflash power determined the optimal operating conditions of the cyclone separator and the flash vessel. The greatest amount of electricity can be generated by operating the cyclone separator at $205^{\circ} \mathrm{C}$ and the flash vessel at $125^{\circ} \mathrm{C}$.

There is a vast amount of potential for geothermal energy to supplement the future energy market. In order for this potential to be realized, initiative must be taken to fund and research EGS technology. This will further the process of making Enhanced Geothermal Systems more economically feasible. The 
research and field work being conducted by AltaRock at the Newberry well site is helping to further this development. The hope is that more research will be conducted similar to AltaRock's work at Newberry, and this will allow geothermal energy to provide significant contribution to the U.S. energy infrastructure in the near future.

\subsection{Recommendations}

There are a number of challenges associated with attempting to completely optimize an Enhanced Geothermal System. Probably the most notable challenge is the lack of costing relationships for fractures in engineered reservoirs. Recent progress has been made in this regard with development of GEOPHIRES. GEOPHIRES can be used to determine the levelized cost of electricity for Enhanced Geothermal Systems, and there is coding in the program to account for fracture design. This will be a useful program to use in future optimization studies [Beckers, et al., 2013].

Another recommendation that would simplify the optimization would be to combine the surface plant software, wellbore modeling software, and reservoir design software to be written in one program. In this optimization, TOUGH2 is written in FORTRAN77 while the wellbore model is written in Microsoft Visual Basic. The combination of these two programs could be something to consider for future work.

The first challenge that arises in an optimization project is deciding which variables will be investigated. For an optimization of an EGS, there are numerous variables making it virtually impossible to optimize the system for every variable. In this project, it was decided to leave the total fluid mass flow rate constant. An interesting optimization would arise when varying the total fluid mass flow rate in a set fractured network with respect to reservoir stimulation time. Operating the system at a higher flow rate yields the extraction of more thermal energy; however, this also expedites the depletion of the thermal reservoir. It is my hypothesis that the economics will yield an optimal mass flow rate that extracts adequate thermal energy but does not deplete the reservoir too quickly. 


\section{REFERENCES}

Agarwal, V., "An Integrated Model to Compare Net Electricity Generation for CO2- and Water- Based Geothermal Systems,” Master’s Thesis, West Virginia University, Morgantown, West Virginia, 2010.

AltaRock Energy Gallery, “Newberry EGS Demonstration”, http://altarockenergy.com/gallery.htm, 2012.

Beckers, K.F., Lukawski, M.Z., Reber, T.J., Anderson, B.J., Tester, J.W., “Introducing GEOPHIRES v1.0: Software Package for Estimating Levelized Cost of Electricity and/or Heat from Enhanced Geothermal Systems” Proceedings, Thirty-Eighth Workshop on Geothermal Reservoir Engineering, Stanford University, Stanford, California, February 11-13, 2013, SGP-TR-198.

Calpine Corporation, "Welcome to The Geysers," About Geothermal Energy, http://www.geysers.com/geothermal.aspx, 2012.

Cladouhos, T.T., et al., "Newberry Volcano EGS Demonstration - Phase I Results” Proceedings, ThirtySixth Workshop on Geothermal Reservoir Engineering, Stanford University, Stanford, California, January 31 - February 2, 2011, SGP-TR-1191.

College of Geothermal Professionals, Hungarian Geothermal Advisory Board, History, http://geotermia.lapunk.hu/?modul=oldal\&tartalom=1153177, 2011.

DiPippo, R., Geothermal Power Plants, 2nd ed., 2008.

Geothermal Technologies Program, US DOE Office of Energy Efficiency and Renewable Energy, "Direct Use of Geothermal Energy,” http://www1.eere.energy.gov/geothermal/directuse.html, 2013.

Geothermal Technologies Program, US DOE Office of Energy Efficiency and Renewable Energy, “Electricity Generation,” http://www1.eere.energy.gov/geothermal/powerplants.html, 2012.

Hasan, A.R., and Kabir, C.S., "Wellbore Heat Transport," Fluid Flow and Heat Transfer in Wellbores, 64-73, 2002.

He, X., and Anderson, B.J., "Supply Characterization of Hydro-Geothermal Resources in the Western U.S.” Proceedings, Thirty-Eighth Workshop on Geothermal Reservoir Engineering, Stanford University, Stanford, California, February 11-13, 2013, SGP-TR-198.

Kagel, A., Bates, D., and Gawell, K., (2005), “A Guide to Geothermal Energy and the Environment,” Geothermal Energy Association, Washington, D.C.

Petty, S., Geothermal Energy Protecting the Environment - And Our Future, 9 June 2010, http://altarockenergy.com/projects.htm.

Pruess, K., Oldenburg, C., Moridis, G., TOUGH2 User's Guide, Version 2.0: A numerical simulator for nonisothermal flows of multicomponent, multiphase fluids in one, two, and three-dimensional porous and fractured media, DOE Contract DE-AC03-76SF00098, Lawrence Berkeley National Laboratory, Berkeley, CA, 1999.

Tester, J.W., et al., (2006), "The Future of Geothermal Energy: Impact of Enhanced Geothermal Systems on the United States in the 21st Century," Massachusetts Institute of Technology, DOE contract DEAC07-05ID14517 final report. 
Tiarks, J., Meyer, T., Brown, R., Anderson, B.J., “Low-Temperature Geothermal Resource Utilization for Combined Heat and Power Production: A Case Study for Iowa State University," Proceedings, Thirty-Eighth Workshop on Geothermal Reservoir Engineering, Stanford University, Stanford, California, February 11-13, 2013, SGP-TR-198. 